\title{
Development of Highly Durable Superhydrophobic Coatings by One-Step Plasma Spray Methodology
}

\author{
B. Swain ${ }^{1}$ A. R. Pati $^{2}$ P. Mallick ${ }^{3}$ S. S. Mohapatra ${ }^{2}$ A. Behera ${ }^{1}$
}

Submitted: 4 April 2020/in revised form: 18 November 2020/Accepted: 22 November 2020/Published online: 3 January 2021 (C) ASM International 2021

\begin{abstract}
This study aims to minimize the mechanical, chemical and thermal damages on the blades of a compressor used in aerospace engines by developing a superhydrophobic coating on the blade surface. In the absence of any information in open literature for the fabrication of such coatings, an one-step plasma spray process was implemented. For this, a well mixed powder of $\mathrm{Ni}$ and $\mathrm{Ti}$ was used as feedstock material. The superhydrophobicity characteristic of the coating was confirmed by the measurement of the contact $\left(165^{\circ}\right)$ and sliding angles $\left(8 \pm 1^{\circ}\right)$ by the sessile drop technique. The adhesion test of the coating showed the high force of adhesion at the interface with a failure limit of $40.85 \mathrm{MPa}$. Furthermore, the abrasion test depicted an excellent abrasion resistance of the coating. These two investigations indicated that the coatings had a very high mechanical durability. The coatings also showed an excellent thermal stability up to $400{ }^{\circ} \mathrm{C}$. Beyond this temperature (at 600 and $900{ }^{\circ} \mathrm{C}$ ), the superhydrophobic characteristic changed for hydrophobic. The $\mathrm{pH}$ and corrosion tests were also performed to assess the chemical stability of coatings. They showed that the coatings retained the superhydrophobic property for $\mathrm{pH}$ ranging between 9.5 and 2.4. Beyond this range, at $\mathrm{pH}=$ 10 and $\mathrm{pH}=2$, the contact angles were $138^{\circ}$ and $143^{\circ}$,
\end{abstract}

S. S. Mohapatra

mohapatras@nitrkl.ac.in

1 Department of Metallurgical and Materials Engineering, National Institute of Technology, Rourkela 769008, India

2 Spray Boiling Heat Transfer Laboratory, Department of Chemical Engineering, National Institute of Technology, Rourkela 769008, India

3 Thermal Spray Division, Hindustan Aeronautics Limited, Koraput 769008, India respectively. In addition, the coatings exhibited a better corrosion resistance than the substrate and coatings developed by using other deposition techniques.

Keywords aeroengines $\cdot$ droplet impingement $\cdot$ nickel · plasma coating $\cdot$ superhydrophobic $\cdot$ titanium

\section{Introduction}

The droplet behavior on lotus and colocasia esculenta leaf surface is considered as the main inspiration and the first scientific theory which is considered as the origin of the development of superhydrophobic surface (Ref 1). The surface depicting a water contact angle greater or equal to $150^{\circ}$ is called superhydrophobic surface ( $\left.\operatorname{Ref} 2,3\right)$, and it is also defined in terms of various forces such as capillary and viscous (Ref 4).

For the attainment of minimum chemical, thermal and mechanical damages (Ref 5-8) in compressor blade used in the aerospace engine, the compressor blade surface needs depict characteristic such as anti-icing, de-icing, self cleaning, water droplet repellency and fog resistance characteristics. As the abovementioned properties are depicted by a superhydrophobic surface, to mitigate the requirements of a compressor blade of aerospace engine, the creation of superhydrophobic coating on the surface of the compressor blades is followed. The above discussed properties depend on the coating fabrication methodology. Hence, in the current investigation, by revealing the fabrication process, the requirements of compressor blade used in aerospace engine are tried to mitigate.

In the recent years, various methodologies for the fabrication of superhydrophobic surfaces have been revealed (Ref 9-12). The literature discloses that the mechanism of 
creation of superhydrophobic surface involves initially the formation of rough structure on the surface, and then further it is modified by low surface energy materials (Ref 1013) such as polytetrafluoroethylene, fluorocarbons, fluoroalkyl-silane and hydrophobic silica (Ref 10-15). Based on the above discussed mechanism, various processes have been developed for the preparation of superhydrophobic surfaces which include lithography patterning (Ref 16), layer-by-layer deposition (Ref 17), chemical vapor deposition (Ref 18), sol-gel (Ref 19), anoidic-oxidation (Ref 20), mold fabrication-hot embossing process (Ref 21), etc.

With the help of the abovementioned process, the fabrication of highly durable superhydrophobic surfaces is extremely challenging task due to the fragile nature of microscopic rough surfaces which are easily damaged by abrasion and corrosive environment (Ref 22, 23). In addition to the above, the excessive dependency of the surface on the surface morphology and chemical composition leads to increment of damage by sun bleaching and scratches (Ref 24). To overcome the stated difficulties, ceramic and metallic based hydrophobic coating is prescribed (Ref 25, 26). Still, the proposed and unmodified methodologies do not fulfill the requirement of blades of aerospace. Therefore, in the current work, an attempt has been made to develop superhydrophobic coating on blades of the aerospace engine by using a technique which is cost effective and also fulfills all the requirements mentioned above.

Thermal spray is a widespread approach to deposit a melted material on the substrate to form a coating (Ref 2730). The described technique improves the adhesion strength by mechanical interlocking between two different materials (Ref 31-35). Among all the thermal spray processes, the atmospheric plasma spray (APS) is a prominent coating method for industrial applications such as aerospace (Ref 36), naval (Ref 37), biomedical (Ref 38) and automotive (Ref 39) due to its capacity to work at open atmosphere and to coat intricate parts. In conjunction with all the applications, the development of superhydrophobic coating is also achieved by plasma spray coating. Many literatures are reported regarding fabrication of superhydrophobic coating by both one-step and two-step method using thermal spray technology. Liu et al. (Ref 9) developed a coating by using thermal sprayed MCrAlY and then another coating layer of perfluorooctyltrichlorosilane was provided to make the surface superhydrophobic. Furthermore, Sharifi et al. (Ref 40) prepared a superhydrophobic coating by both APS and SPS process and applied a low surface energy material on the coating to make it superhydrophobic. Again, Huang et al. (Ref 41) developed a coating by APS method and then treated the surface with $1 \mathrm{H}, 1 \mathrm{H}, 1 \mathrm{H}, 2 \mathrm{H}$ perfluorodecyltrimethoxysilane to prepare a superhydrophobic surface. In all the reported two-step methods for superhydrophobic surface preparation, the use of low surface energy material restricts the application of the coating in extreme conditions. In case of two-step process, the developed coating durability is not significant and also not economical for the aerospace application. The cost factor for fabrication of superhydrophobic coating by APS can be minimized by the work reported by Li et al. (Ref 42), but the fluffy structure of the used polymer declines its durability. Due to the abovementioned reason, in APS method, use of polymer is not recommended to get highly durable coating. Furthermore, in the absence of any information related to the development of superhydrophobic coating of metals/ceramic by one-step APS process, the most relevant information is given by Li et al. (Ref 43). According to them, the presence of organic particles on the surface of the coating promotes superhydrophobicity. They developed a superhydrophobic surface by spraying a mixture of $\mathrm{Fe}, \mathrm{Ni}$ and $\mathrm{Cr}$. However, this composition is not recommended for the aerospace application although the durability of coating is considerable for the mentioned specific application. Therefore, in the current work, by using single step plasma coating process, a mechanically, thermally and chemically durable coating of Ni55Ti45 (wt.\%) [also known as smart material (Ref 44-46)] is tried to develop, and this coating is expected to mitigate the requirement of aerospace industry (Ref $43,47,48$ ). As Ni and $\mathrm{Ti}$ are used in the coating process, the expected hardness is very high and as a result the mechanical damage due to attrition is minimum (Ref 49). Furthermore, the melting point and thermal stress absorbing capacity of Ni55Ti45 are also very high (Ref 50,51), and from these it is expected to retain its superhydrophobic property up to very high temperature.

In the current work, by using one-step APS method, highly mechanically, chemically and thermally durable and stable coating is tried to develop. The various characterizations of the developed coating were also performed to identify its applicability in the aerospace industry.

\section{Materials and Methods}

\section{Atmospheric Plasma Spray (APS)}

The NiTi coating was developed on a mild steel (AISI1018) substrate $(5 \mathrm{~cm} \times 4 \mathrm{~cm} \times 0.5 \mathrm{~cm})$ by using an atmospheric plasma spray system (Oerlikon Metco (Switzerland) using a F4MB gun (with a 6-mm nozzle diameter) (Hindustan Aeronautics Limited, Koraput, Odisha, India)). Plasma was generated by using a mixture of argon (Ar) and hydrogen $\left(\mathrm{H}_{2}\right)$ gases. Furthermore, another pure argon (Ar) gas stream was used as a carrier to 
transport the Ni-Ti powder particles to the plasma spray gun. During the coating process, the carrier gas stream flow rate was maintained at $3.5 \mathrm{~L} / \mathrm{min}$ (LPM) according to the information reported in the literature (Ref 52, 53). Before coating, for the attainment of better adhesion strength, average surface roughness up to $10.57 \mu \mathrm{m}$ was created on the substrate. For this sand blasting was done using $\mathrm{Al}_{2} \mathrm{O}_{3}$ grits. Furthermore, the substrate was preheated up to a temperature of $120^{\circ} \mathrm{C}$ by plasma spray gun to obtain a well-formed splat without any finger formation.

By using a turbula mixture, a mixture of elemental $\mathrm{Ni}$ (Metco $56 \mathrm{VC},-150+45 \mu \mathrm{m}$ ) and Ti (Sulzer Metco $4017,-180+53 \mu \mathrm{m})(99.9 \%$ purity) was prepared after continuously operating for $6 \mathrm{~h}$. Before the coating process, the characterization of feed stock powder was performed. The morphology by SEM (500X) reveals the shape of the particles, and the EDS spectra indicate the purity of the feed stock powders (Fig. 1). From this, it is noticed that the size distribution of the nickel powder particles is nonuniform. Furthermore, it mimics the shape of a chip. In addition to the above, it is also observed that the titanium powder particles have formed sharp edges. Therefore, the resultant shape can be considered as the angular shape. Particle size distribution of $\mathrm{Ni}$ and $\mathrm{Ti}$ powder has been shown in Fig. 2. From the analysis of distribution curve, the obtained mean particle diameter $\left(d_{50}\right)$ for $\mathrm{Ni}$ and $\mathrm{Ti}$ is 35.27 and $33.93 \mu \mathrm{m}$, respectively.

During the preparation of coating, the powder was injected externally to the plasma torch in a direction which is perpendicular to the flow of plasma and parallel to the trajectory of the plasma torch. After the injection of powder particles into the torch, the metal powder converted to molten/semi-molten state and on the mild steel substrate during to and fro motion of plasma torch. The stand-off distance was kept at $120 \mathrm{~mm}$ during coating according to the information reported in the literature. In the current work, seven cycles were used for the preparation of coating. A rapid solidification (at a rate of $10^{6} \mathrm{~K} / \mathrm{s}$ ) of the molten particles has been occurred after impact on the substrate surface and predeposited splat. APS process parameters are given in Table 1.

Before experimentation, the morphological study of the raw materials (powder) was carried out by field emission scanning electron microscope (FESEM). After experimentation, the qualitative and quantitative analysis of the coatings was performed by using various characterization techniques. The surface topography of the NiTi coating was analyzed by scanning electron microscope (SEM) (model: JEOL 6480LV) which is equipped with energy dispersive spectroscopy (EDS) for the determination of elemental composition. With the help of (Co-Ka $(\lambda=1.79 \AA)$ radiation, (generated at $35 \mathrm{kV}$ and $25 \mathrm{~mA}$ ) the phase analysis was performed using $\mathrm{x}$-ray diffraction technique (XRD) (Bruker D8 Advance). For this, the scan

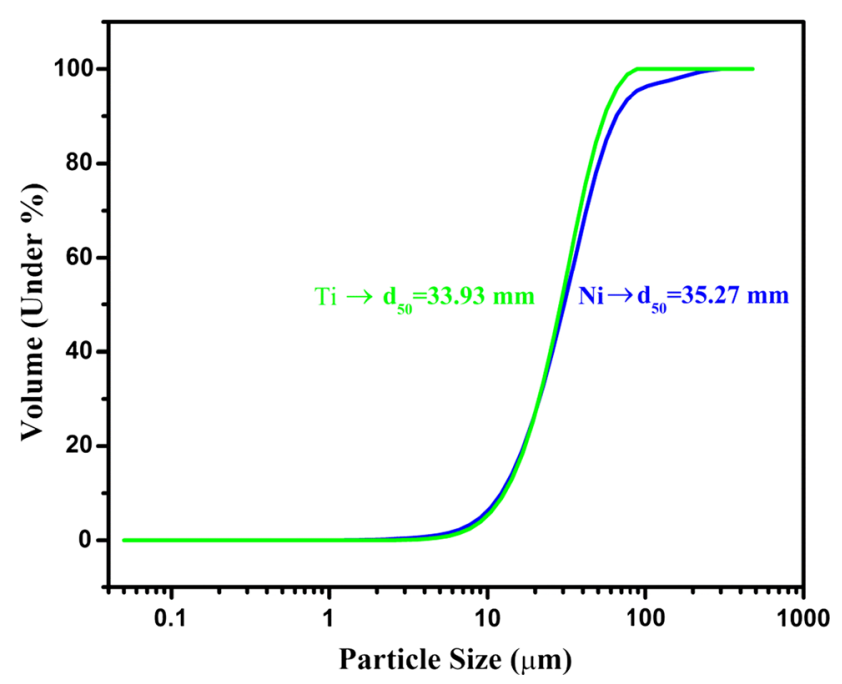

Fig. 2 Particle size distribution of both Ni and Ti powders
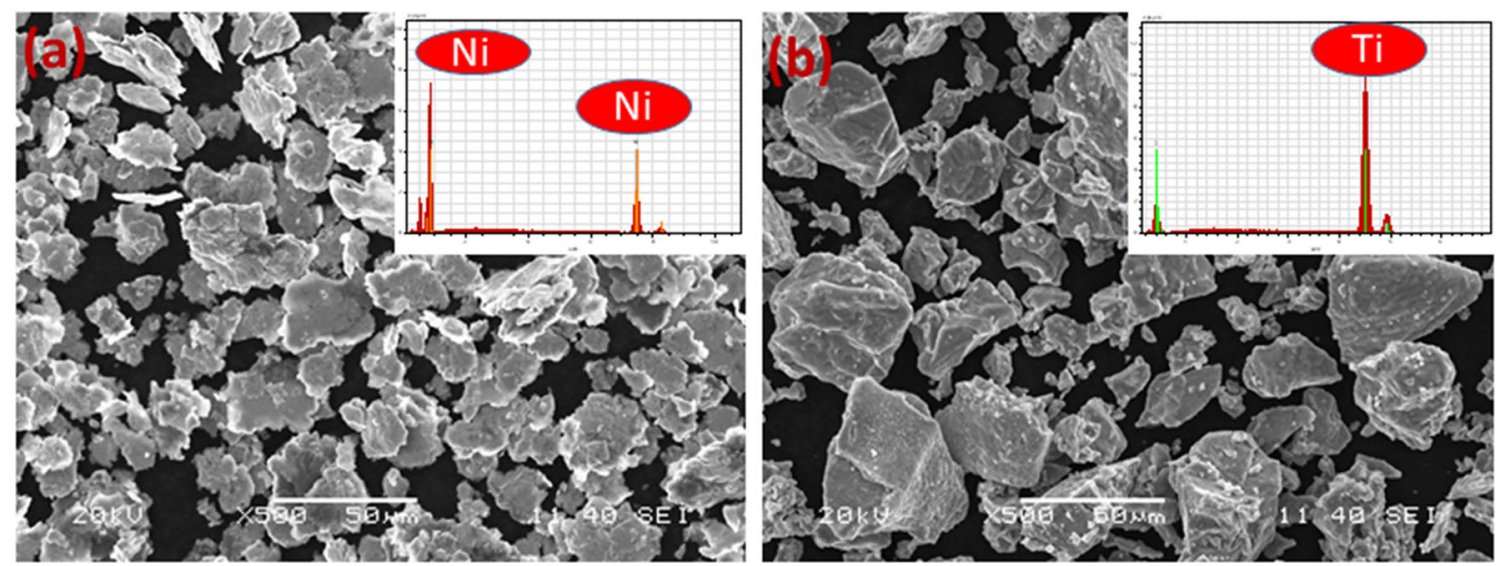

Fig. 1 SEM morphology of raw (a) Ni (the inset is the EDS spectra of Ni) and (b) Ti (the inset is the EDS spectra of Ti) powders. (Magnification: $\times$ 500) 
Table 1 Atmospheric plasma spray parameters

\begin{tabular}{lll}
\hline \multicolumn{1}{c}{ APS parameters } & \multicolumn{1}{c}{ Values } & \multicolumn{1}{c}{ Justification } \\
\hline Substrate temperature & $120{ }^{\circ} \mathrm{C}$ & \\
Powder feed rate & $60 \mathrm{~g} / \mathrm{min}$ & \\
Primary gas (Ar) flow rate & $45 \mathrm{~L} / \mathrm{min}$ & \\
Carrier gas (Ar) flow rate & $3.5 \mathrm{~L} / \mathrm{min}$ & \\
Secondary gas $\left(\mathrm{H}_{2}\right)$ flow rate & $8 \mathrm{~L} / \mathrm{min}$ & \\
Stand-off distance & $120 \mathrm{~mm}$ & \\
Number of cycles & 7 & \\
Current & $550 \mathrm{~A}$ & \\
Voltage & $70 \mathrm{~V}$ & \\
\hline
\end{tabular}

rate, two theta range and step size were $10^{\circ} / \mathrm{min}, 20-110^{\circ}$ and 0.02 , respectively. In addition to the above, the surface micro hardness of the coating was measured by LECO micro hardness tester (LM248AT) at a load of $100 \mathrm{gf}$ (dwell time $10 \mathrm{~s}$ ). Furthermore, to quantify the irregularities (roughness) present on the surface of the coating, measurement of surface roughness was also carried out using stylus surface profilometer (Veeco dektak 150) containing Leica DM microscopy with Carl Zeiss lens. The maintained operating parameters for the abovementioned were: (1) stylus radius $=12.5 \mu \mathrm{m}$, (2) length $=2000 \mu \mathrm{m}$ and (3) force $=2 \mathrm{mg}$. Furthermore, a 3D optical surface profiler (Contour GT-K (Bruker make) USA) was also used to get a 3D surface topography of the coating. In addition to the above analysis, on the coated surface, the static contact and sliding angles of the impinged droplet were measured by using a goniometer ((Model no: Kruss DSA 25)) and an indigenously designed and fabricated sliding angle measuring apparatus, respectively.

For the quantification error, all the experiments and measurements were conducted thrice, and the average values were reported. Before measurement, (contact angle, roughness, $\mathrm{pH}$, adhesion, abrasion and corrosion test) each measuring instrument was calibrated and after ensuring maximum error less than $1 \%$ the measurements were conducted. Measurement and characterization (XRD and SEM) related to hydrophobicity characteristic identification clearly follow the protocols reported in ASTM standards.

\section{Results and Discussion}

\section{Characterization of Coated Material}

\section{XRD Analysis}

XRD analysis (Fig. 3) reveals the presence of different phases (TiO, NiO, NiTi-B2, Ni, Ti, $\mathrm{Ni}_{3} \mathrm{Ti}_{2}, \mathrm{Ti}_{2} \mathrm{Ni}$ and $\mathrm{Ni}_{4}$ $\mathrm{Ti}_{3}$ ) in the NiTi plasma sprayed coating. $\mathrm{TiO}$ and $\mathrm{NiO}$ are

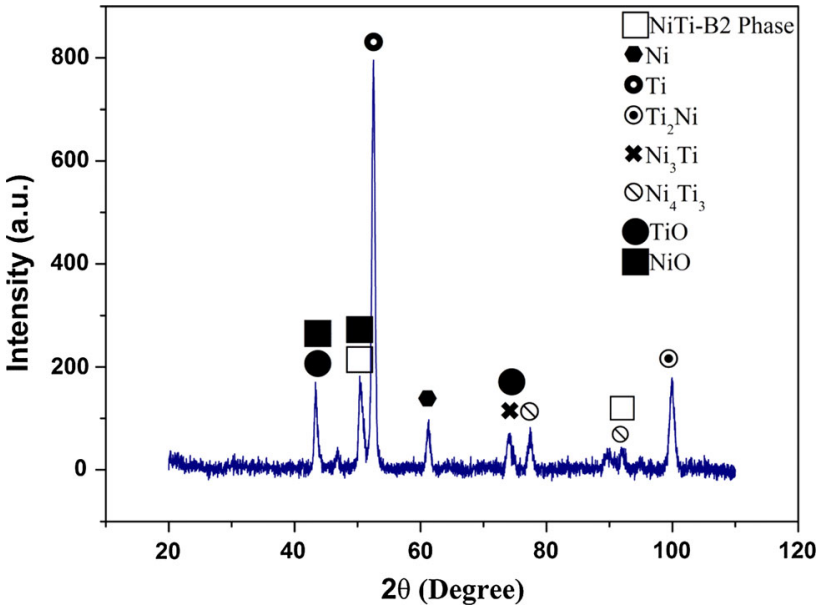

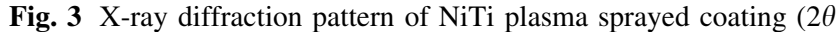
range $=20-110^{\circ}, \mathrm{Scan}$ rate $=10^{\circ} / \mathrm{min}$ and Step size $=0.02$ ) layer-bylayer accumulation characteristic of the particles

the oxide phases present in the coating due to operation at high temperature and open atmospheric condition. Titanium alloys have very much high affinity for oxygen, and as a consequence these oxide phases are achieved. Furthermore, peaks for pure $\mathrm{Ni}$ and $\mathrm{Ti}$ peaks are also identified in the coating. This is due to the use of an elemental mixture of nickel and titanium as the feedstock material. The splats of both the powders form individually or by overlapping one over another due to the development of concentration gradient which allows the individual metal to diffuse and accumulate (Ref 56, 57). In addition to the above, it is also expected that at some locations, force of cohesion dominates over the force of adhesion, and the vice versa is also expected in few locations. This could be another reason for the attainment of the above mention characteristic in coating (Ref 58,59). The NiTi-B2 phase is the austenitic phase of NITINOL shape memory alloy which is present in the developed coating. The crystal structure and space group of above-stated phase are cubic and $\mathrm{Pm}-3 \mathrm{~m}$, respectively. This phase is present in the (011) and (002) plane in the developed coating. $\mathrm{Ti}_{2} \mathrm{Ni}$ and 
Fig. 4 (a) SEM morphology $(\times 500)$ (inset contact angle image) (b) and (c) EDS spectra of the coating and (d) 3D optical image of the coating (a)
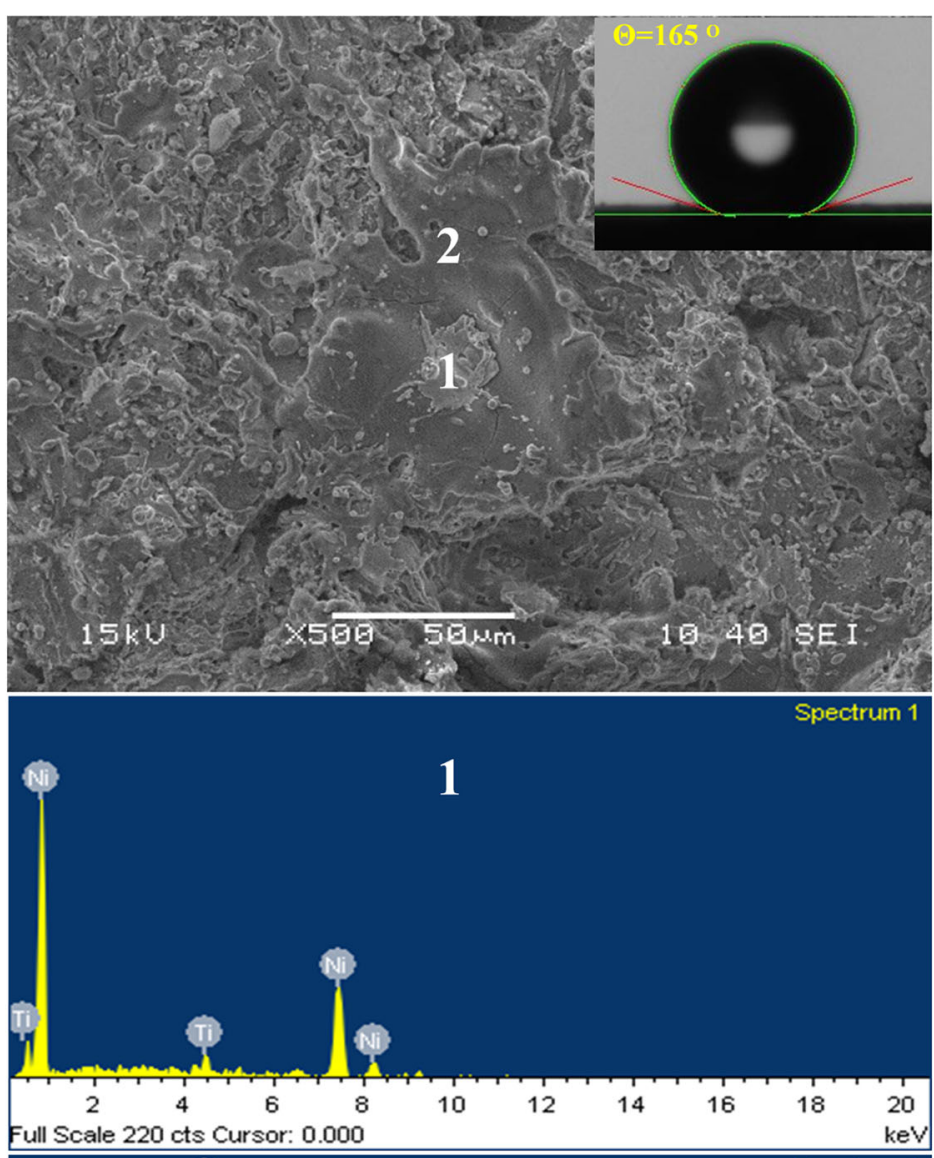

(b)

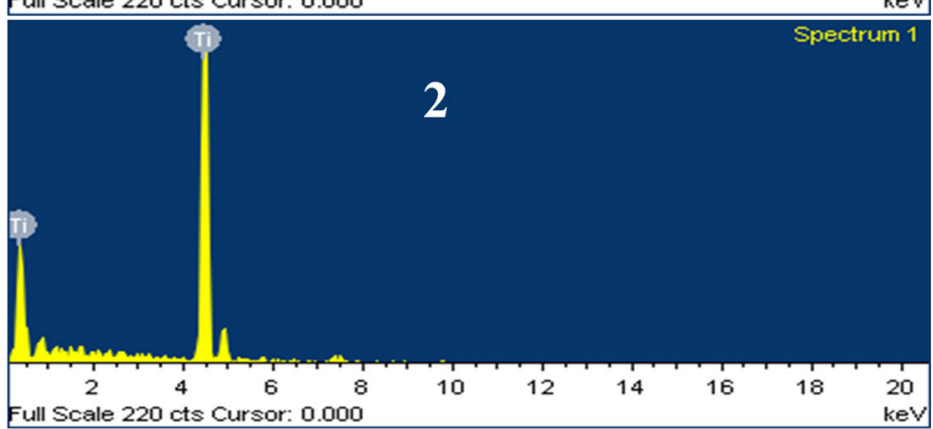

(c) Eull Scale $220 \mathrm{cts}$ Cursor: 0.000

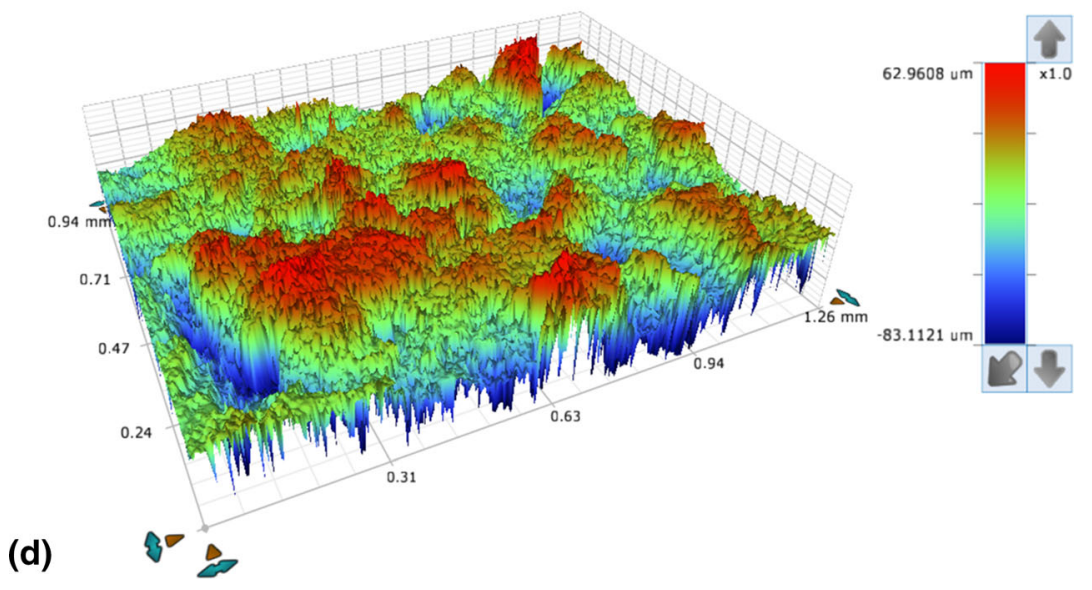



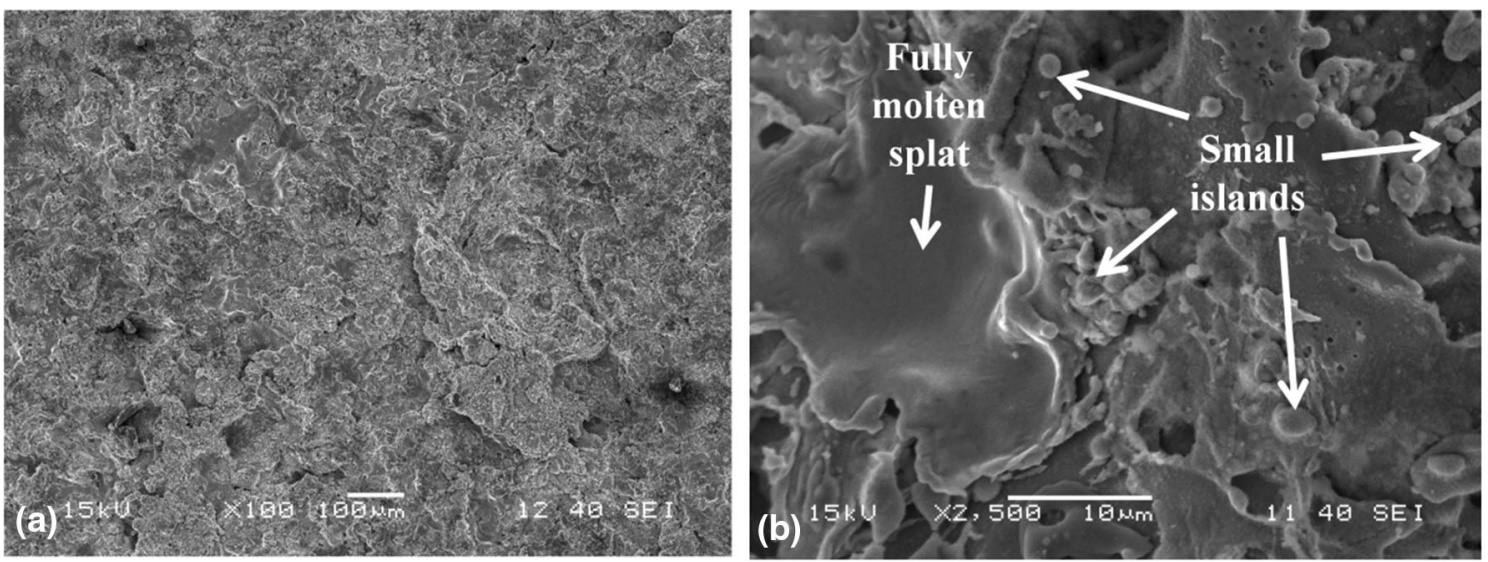

Fig. 5 SEM morphology of NiTi plasma spray surface at (a) low and (b) high magnification

$\mathrm{Ni}_{3} \mathrm{Ti}$ form by eutectoidally decomposition of $\mathrm{NiTi}$ (Ref 60).

The formation of the new compound after the development of the coating clearly indicates the alteration of structural orientation on the surface of the coating. The discussed modification may lead to enhance of surface roughness or create uniformity in surface texture.

\section{Surface Morphology Analysis of the NiTi Plasma Coating}

The surface morphology (Fig. 4a) shows that the microcavities are present on the surface of the coating. Hence, the irregularities need to be quantified in terms of average surface roughness. This was measured by using stylus surface profilometer, and the achieved value is $8.78 \mu \mathrm{m}$. In addition to the above, for the further clarification, the 3D profile of the rough surface is provided (Fig. 4d) to get better idea about the variation of pillars creating roughness. The roughness is mainly due to the splat edges.

The SEM topography also reveals that the coating contains well-formed splat. During coating formation, the melted metal particles formed splat and the unmelted amount accumulate or deposit at discrete locations. This could be due to the improper heat transfer between either plasma to particles or particle to particle. Furthermore, the deposition of the unmelted particle is also considered as a source of surface irregularities defining surface roughness. In the current work, the layer-by-layer splat formation during the plasma deposition cycle enhances the surface roughness due to the cumulative effect of various splat layers. The surface morphology of the NiTi plasma sprayed coating was analyzed by SEM images, and the elemental analysis at the corresponding regions has been determined by EDS spectra. From the abovementioned analysis, it is concluded that the splat elemental composition in regions 1 (Fig. 4b) and 2 (Fig. 4c) is $\mathrm{Ni}$ and $\mathrm{Ti}$ and only $\mathrm{Ti}$, respectively. The result reflects the low and high magnification SEM micrographs (Fig. 5a and b) are given to observe the microstructural effect on the superhydrophobicity characteristic of the coating. The formation of small islands can be noticed from Fig. 5(b). Splashing of fully molten particles upon impinging with the substrate is one of the reasons behind the formation of small islands (Ref 61, 62). Furthermore, the deposition of semi-molten or partially molten particles due to improper heat transfer is another reason for the formation of small islands. In addition to the above, according to $\mathrm{Li}$ et al. (Ref 43) the deposition of organic material due to the adsorption from the air on the coating surface can be considered as the another reason for the development of superhydrophobic characteristic.

Figure 6(a) is the backscattered image of the NiTi coating. The overlapping of the titanium on the nickel splat is confirmed from the inset in Fig. 6(a), and the composition is confirmed from EDS spectra (Fig. 6b and c). It can be observed from the SEM image that the particles are completely melted to form splat. The major disadvantage of the coating is evident from the microcracks identified from the SEM images captured in backscattered mode. These microcracks could be due to the difference of coefficient of thermal expansion between the coating and substrate material or between phases with in the coating (Ref 63).

The presence of microroughness on the surface of the coating creates partially slip condition according to the fluid dynamics theory favors of repellency characteristic according to the Cassie Baxter theory, which is considered as the main mechanism for the creation of superhydrophobic character. The theory is validated by measuring contact angle is $165 \pm 1.5^{\circ}$ and the sliding angle $8 \pm 1^{\circ}$.

For the further strengthen the discussion, the droplet behavior after impingement is analyzed in terms of fluid dynamic theory and energy balance concept. Initially, the 

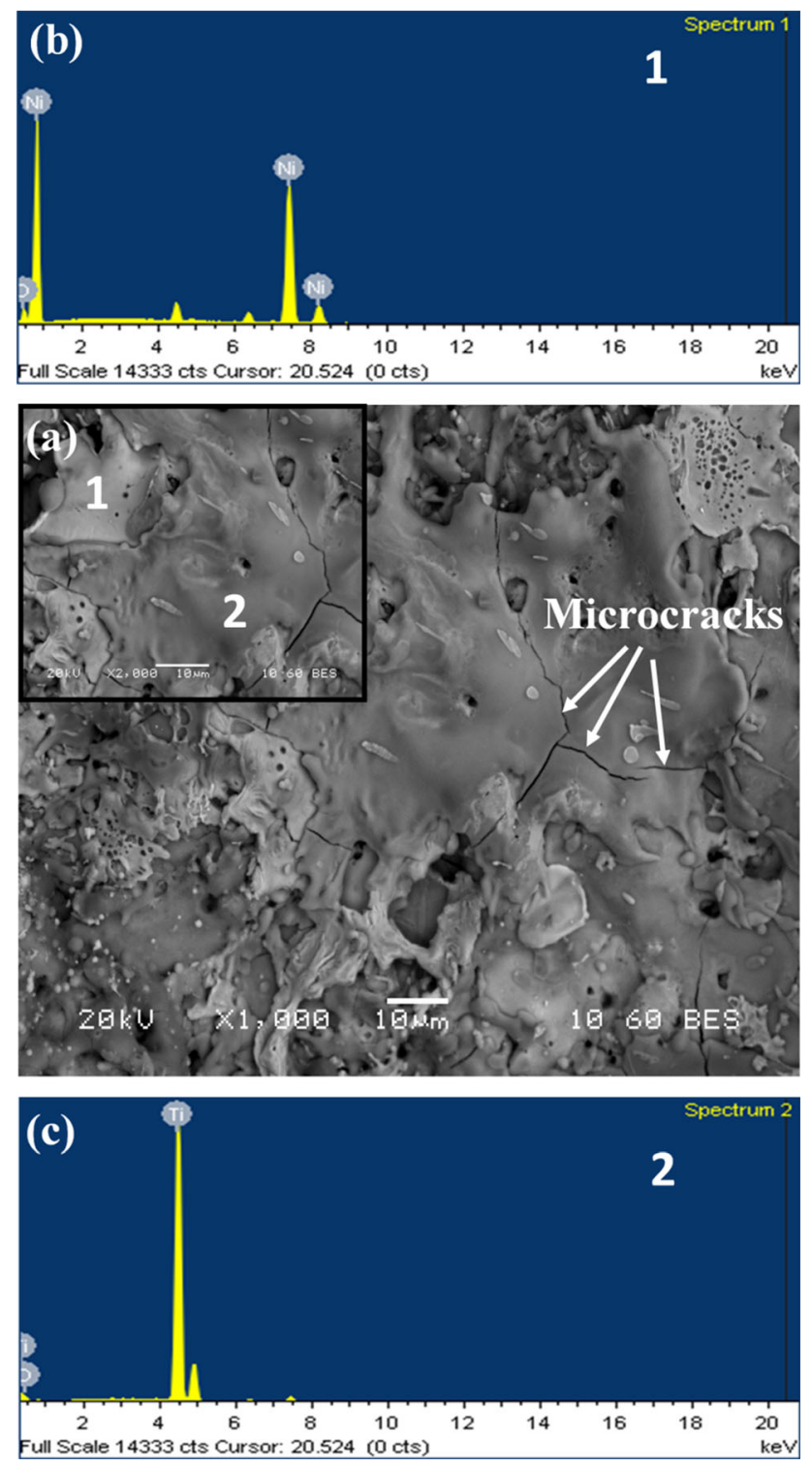

Fig. 6 (a) Surface micrograph of NiTi coating observed by SEM (magnification: $\times 1000)$ in BES mode with $(b$ and $c)$ corresponding EDS spectra behavior is explained in terms of fluid dynamics and then in the form of energy balance principle.

In case of plasma coating, after impingement of droplet, due to the presence of microroughness in the form of micro-cavity on the surface, the slip condition (Eq 1) creates buoyancy force in the opposite direction of the impingement (Fig. 7). As a result, the impinged droplet finds repellency characteristic. This phenomenon enhances the contact angle by promoting recoiling characteristic.

According to fluid dynamics, for slip condition,

$u \neq 0 \quad$ at $\quad y=0 \quad$ (Point of contact)

where $u$ is the velocity in $y$ direction, $x$ and $y$ are coordinates indicates the direction and qualitative magnitude of the velocity.

In addition to the above phenomena, the particle size distribution of the powder used for the plasma spray is also another important factor defining the surface properties. Generally the mixture contains particle of various diameter. In case of bigger size particle sometimes the melting process impedes. Due to this, during solidification, the partially molten metal particle forms big pillar. The reverse trend is expected if the molten metal contains small particles. The small particles in the mixture could not enter into the flame center (Ref 64, 65) and as a consequence partial melting is observed. This phenomenon is considered as reason for the formation of small pillar (Ref 61, 62). As the variation in height of the pillars defines the roughness, the aforesaid statement is considered in one-step method for the creation of rough surface depicting superhydrphobic character.

According to the literature, the superhydrophobicity is described in terms of contact angle or various forces such as viscous and capillary. Already using the first concept the coating properties have been evaluated. For the evaluation of the coating characteristic in terms of second theory viscous and capillary forces have been calculated (Ref 4) by using Eq 2-11. All the above-stated forces are calculated from the nondimensional numbers such as Weber
Fig. 7 Superhydrophobicity and slip condition for superhydrophobic surface and for general case

\section{Superhydrophobic surface}

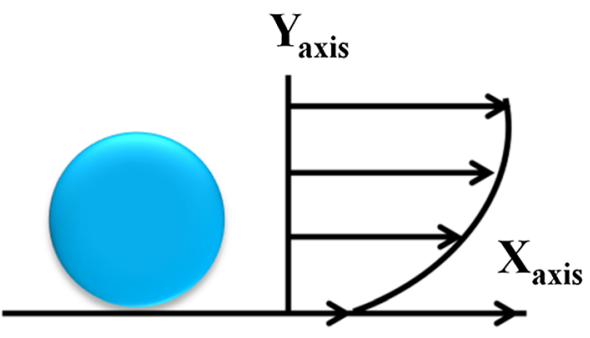

$u=$ finite at $x=0$ and $y=0$

\section{Other surface}

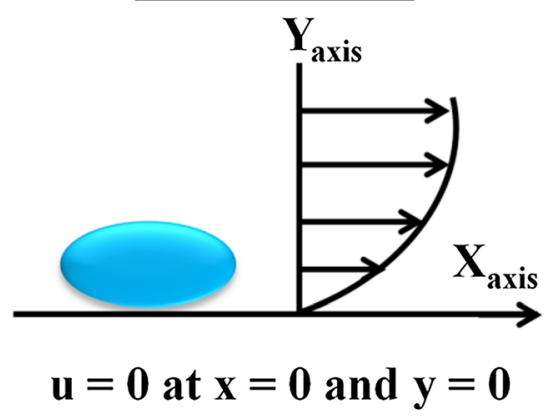




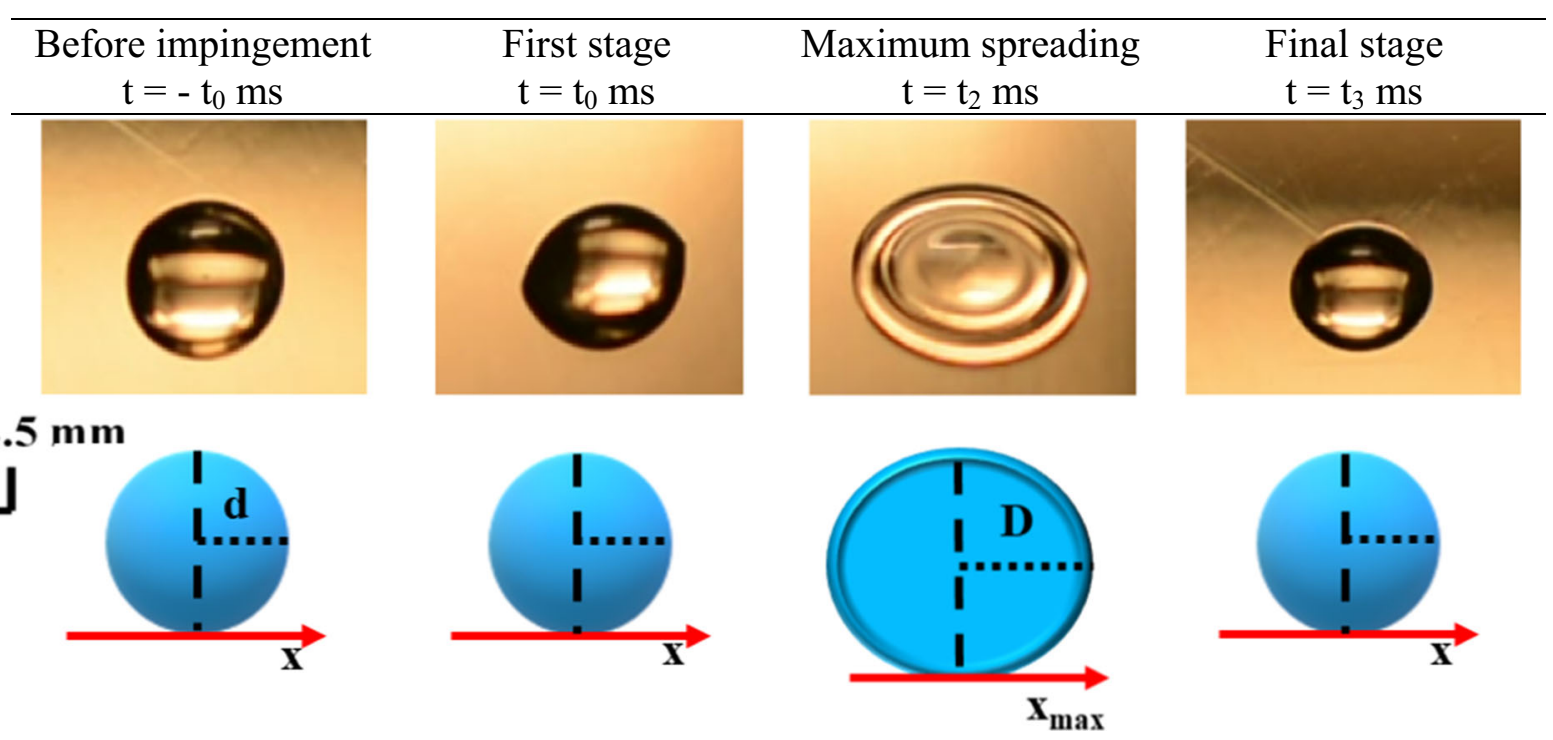

Fig. 8 Images and schematics indicating the measurement procedure

Table 2 Parameters controlling wettability

\begin{tabular}{|c|c|c|c|c|c|c|c|c|c|}
\hline $\begin{array}{l}\text { Velocity, } \\
\mathrm{m} / \mathrm{s}\end{array}$ & $\begin{array}{c}\mu, \\
\mathrm{MPa} \mathrm{s}\end{array}$ & $\begin{array}{c}\sigma, \\
\mathrm{mN} / \mathrm{m}\end{array}$ & $\begin{array}{l}\rho, \mathrm{kg} / \\
\mathrm{m}^{3}\end{array}$ & $\begin{array}{c}\text { Maximum spreading } \\
\text { diameter }\left(X_{2}\right), \mathrm{m}\end{array}$ & $\begin{array}{l}\text { Final spreading } \\
\text { diameter, } m\end{array}$ & $\begin{array}{l}\text { Spreading } \\
\text { factor }(\beta)\end{array}$ & $\begin{array}{l}\text { Droplet diameter } \\
\qquad(d), \mathrm{mm}\end{array}$ & $\begin{array}{l}t_{1}, \\
\mathrm{~ms}\end{array}$ & $\begin{array}{l}t_{2}, \\
\mathrm{~ms}\end{array}$ \\
\hline 0.0121 & 0.98 & 72.8 & 997 & 0.0012 & 0.00119 & 0.31 & 2.5 & 196 & 201 \\
\hline
\end{tabular}

Table 3 Comparision of current work and literature

\begin{tabular}{|c|c|c|c|}
\hline \multicolumn{2}{|c|}{ Current work } & \multicolumn{2}{|c|}{$\begin{array}{l}\text { Panda et al. (Ref } 4) \\
\text { For superhydrophobic character }\end{array}$} \\
\hline$P_{\mathrm{f}}, \mathrm{N}$ & $S_{\mathrm{f}}, \mathrm{N}$ & $P_{\mathrm{f}}, \mathrm{N}$ & $S_{\mathrm{f}}, \mathrm{N}$ \\
\hline 0.00154 & $2 \times 10^{-7}$ & 0.0016 & $1.9 \times 10^{-7}$ \\
\hline
\end{tabular}

(We) and Reynolds (Re). For the calculation of capillary force $\left(P_{\mathrm{f}}\right)$, inertial force $\left(N_{\mathrm{f}}\right)$ and viscous force $\left(S_{\mathrm{f}}\right)$, the droplet diameters before impingement and various stages after impingement have been calculated with the help of image analysis. From the image analysis, the time required to transit from one stage to another stage has been determined (Fig. 8). Furthermore, the $X_{2}$ distance, the distance covered by the droplet due to maximum spreading, is also
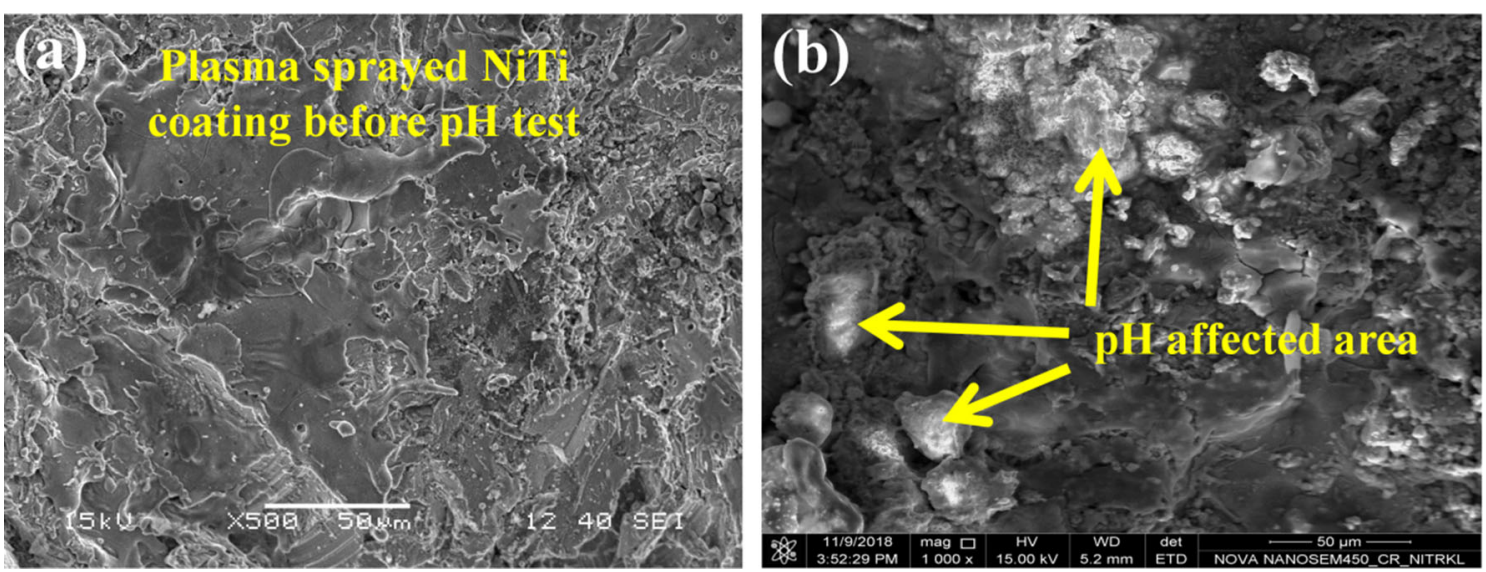

Fig. 9 SEM morphology of the NiTi coating (a) before and (b) after pH test 

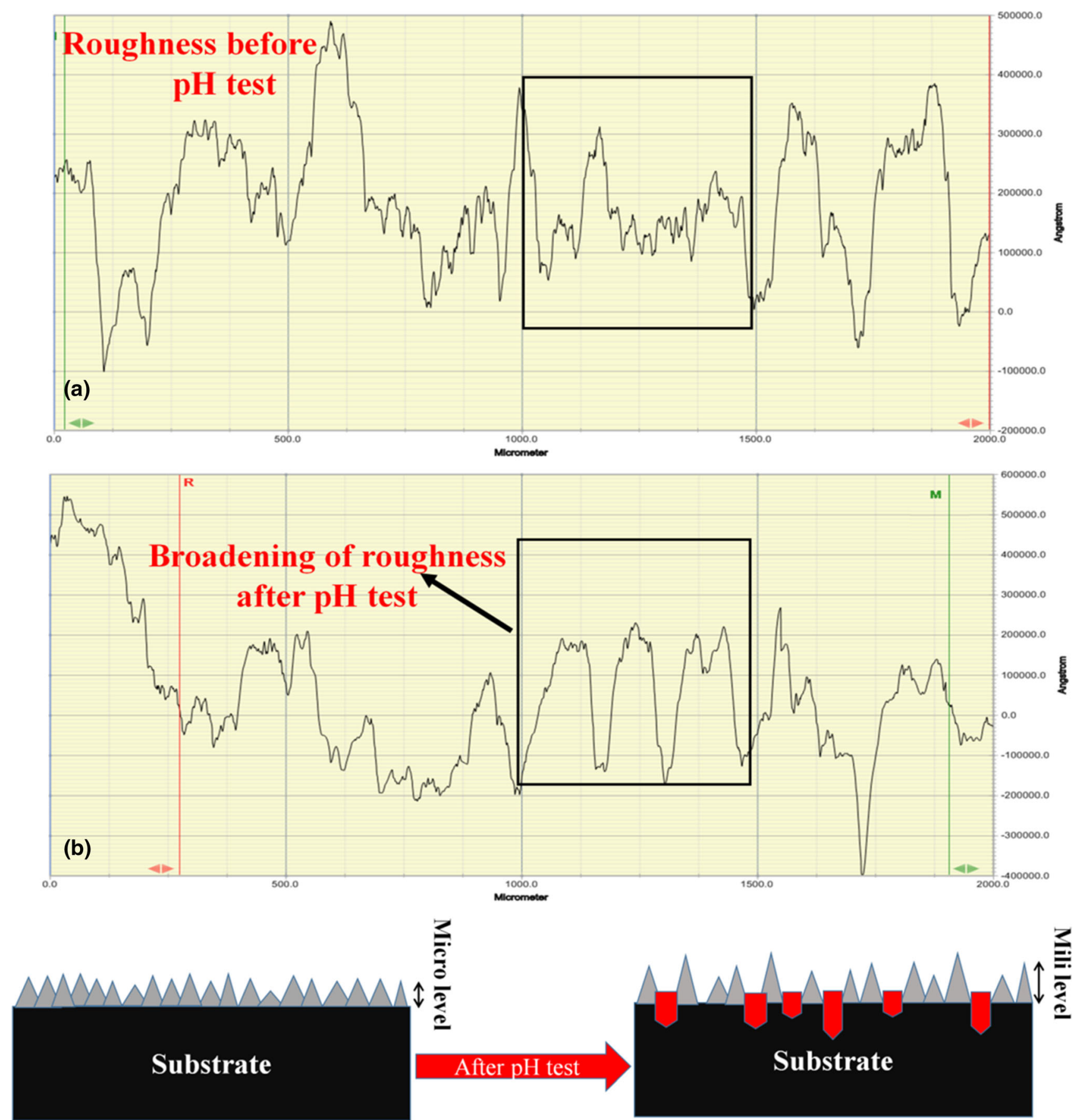

(c)

Fig. 10 (a) Roughess of the coating before $\mathrm{pH}$ test, (b) roughness of the coating after $\mathrm{pH}$ test and (c) schematic depicting broadening phenomenon of the rough surface due to $\mathrm{pH}$ attack

determined by comparing the images of various stages. In addition to the above, for the calculation of fluid properties such as $\mu, \sigma, \rho$ are measured, and mass of the droplet has been calculated by using Eq 8 . The parameters of controlling wettability are given in Table 2 .

After calculation of $P_{\mathrm{f}}$ and $S_{\mathrm{f}}$ (Table 3), these values have been compared with the information reported in the literature. The comparision clearly ensures that the achieved values lie in the superhydrophobic regime.

$\mathrm{We}=\frac{\text { Inertia force }}{\text { capillary force }}=\frac{N_{\mathrm{f}}}{P_{\mathrm{f}}}$ 


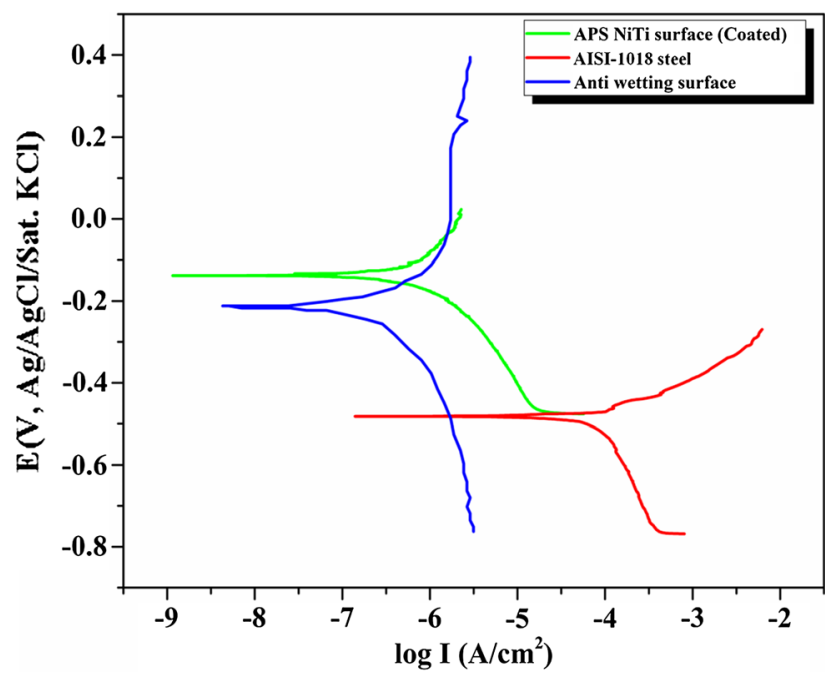

Fig. 11 Polarization curve of the surface with or without APS NiTi coating and antiwetting surface (scan rate $=0.166 \mathrm{mV} / \mathrm{s}$ )

Table 4 Atmospheric condition stability of superhydrophobicity

\begin{tabular}{ll}
\hline Atmospheric conditions & Amount \\
\hline Temperature & $34-40{ }^{\circ} \mathrm{C}$ \\
Pressure & $1 \mathrm{~atm}$ \\
Humidity & $80-91 \%$ \\
\hline
\end{tabular}

$\operatorname{Re}=\frac{\text { Inertia force }}{\text { Viscous force }}=\frac{N_{\mathrm{f}}}{S_{\mathrm{f}}}$

$S_{\mathrm{f}}=\frac{\mathrm{We}}{\mathrm{Re}} \times P_{\mathrm{f}}$

where $N_{\mathrm{f}}=$ inertia force, $\mathrm{N} ; S_{\mathrm{f}}=$ viscous force, $\mathrm{N}$; $P_{\mathrm{f}}=$ capillary force, $\mathrm{N} ; \mathrm{We}=$ Weber number; $\mathrm{Re}=$ Reynolds number.

Re after impingement $=\frac{\text { Inertia force }}{\text { Viscous force }}$

$=\frac{\frac{m\left(v_{2}-v_{1}\right)}{t}}{\text { Viscous force }}=\frac{v \rho l}{\mu}=\frac{\left(\frac{v_{1}+v_{2}}{2}\right) \times \rho D_{\mathrm{f}}}{\mu}$

where $\mu=$ viscosity of the fluid, (m Pas), $\rho=$ density of the fluid, $\left(\mathrm{kg} / \mathrm{m}^{3}\right), D_{\mathrm{f}}=$ final spreading diameter of the fluid, (m), $m=$ mass of the droplet, $(\mathrm{kg}), t=$ Time, (s), $l=$ characteristic length (typically the droplet diameter).

$S_{\mathrm{f}}=\frac{\frac{\frac{m\left(v_{2}-v_{1}\right)}{t}}{\frac{\frac{1}{\left(v_{1}+v_{2}\right)}}{2}} \times \rho D_{\mathrm{f}}}{\mu}$
Table 5 Variation of contact angle with exposure time

\begin{tabular}{lc}
\hline Exposure time, days & Contact angle, \\
\hline 0 & $165 \pm 0.25$ \\
10 & $164.6 \pm 0.35$ \\
20 & $163.7 \pm 0.8$ \\
30 & $162.2 \pm 0.82$ \\
40 & $158.6 \pm 1.07$ \\
50 & $156.9 \pm 0.68$ \\
60 & $155.4 \pm 0.87$ \\
70 & $153.2 \pm 1.18$ \\
80 & $151.5 \pm 1.3$ \\
90 & $148.4 \pm 0.57$ \\
\hline
\end{tabular}

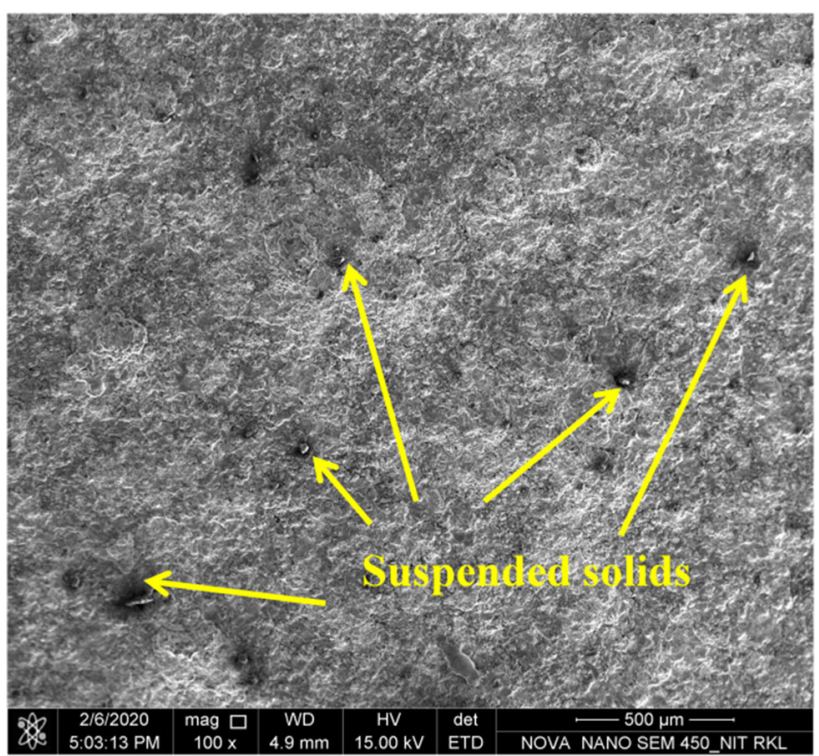

Fig. 12 Identification of deposited solids on the exposed coating to surrounding

Mass of the $\operatorname{droplet}(m)=$ Volume of the droplet $\times$ Density of the solution

$\mathrm{We}=\frac{\text { Inertia force }}{\text { Capillary force }}=\frac{\frac{m\left(v_{2}-v_{1}\right)}{t}}{\sigma \times l}$

Velocity during spreading,

$\frac{X_{2}-d}{t_{1}}=v_{1}$

Velocity during recoiling,

$\frac{X_{2}-D_{f}}{t_{2}}=v_{2}$ 
Fig. 13 Stepwise

experimentation of abrasion test and variation in droplet shapes before and after abrasion test (experimental condition: coating dimension:

$5 \mathrm{~cm} \times 4 \mathrm{~cm} \times 0.5 \mathrm{~cm}$, pressure: $346.5 \mathrm{kPa}$, sandpaper grade: 150 grit $\mathrm{SiC}$ sand paper)
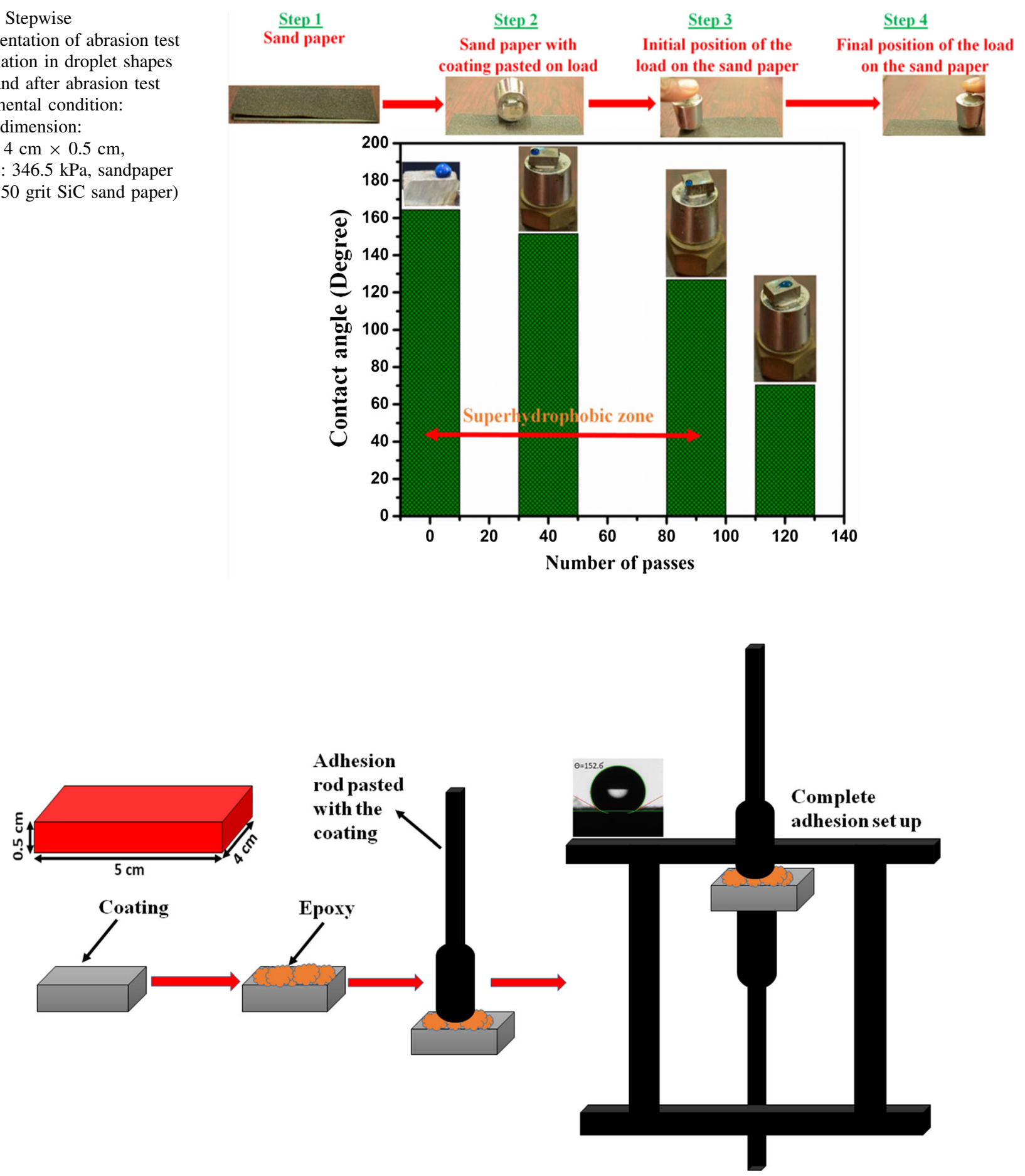

Fig. 14 Schematic diagram of adhesion setup and contact angle image after adhesion test

$V_{1}, V_{2}, D_{\mathrm{f}}$ and $t$ are calculated from the image of the droplet impingement, $\sigma$ is the surface tension of the droplet, $X_{2}$ is the distance covered by the droplet due to maximum spreading.

Where $\beta$ is the spreading factor and is defined as the ratio of diameter of the droplet after spreading to the droplet diameter.

\section{Chemical Stability}

pH Test

To determine the chemical stability of the NiTi plasma spray coatings, these were immersed in both acidic and alkaline solutions. The acidic solution was prepared by 


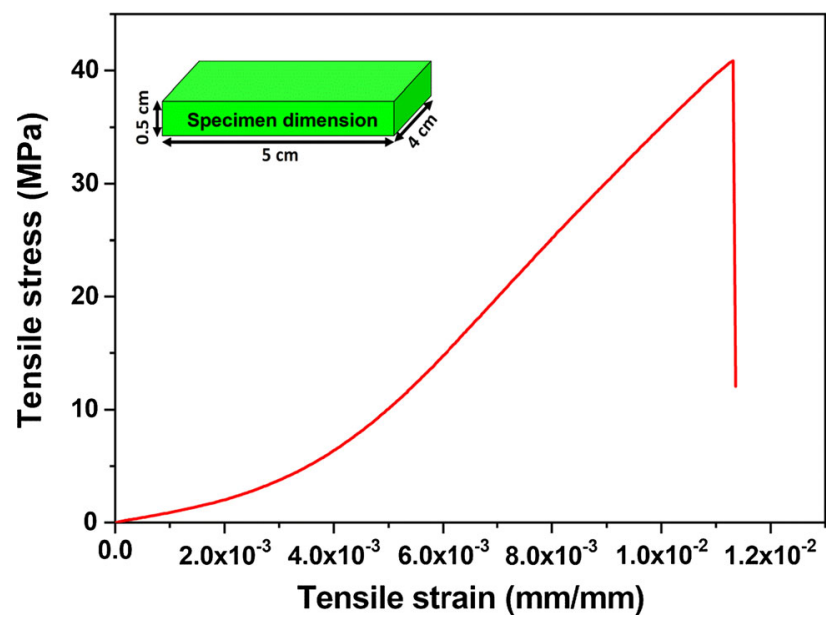

Fig. 15 Variation of tensile stress with strain curve (cross-head speed $10 \mathrm{~m} / \mathrm{min}$ at $1.84 \mathrm{kN}$ load)

diluting concentrated $\mathrm{HCl}$ up to $0.01 \mathrm{M}$ which depicts the presence of very strong $\mathrm{H}^{+}$ion by revealing a $\mathrm{pH}=2$. Similarly, $\mathrm{NaOH}$ solution $(\mathrm{pH}=10)$ solution of $(0.01 \mathrm{M})$ was used in the investigation. The coating was dipped vertically in the solutions for $24 \mathrm{~h}$ under sufficient liquid head. Then, the coatings were brought out from the solution and dried in an oven at room temperature for the removal of moisture. Thereafter, the coatings were cleaned with the help of alchohol before the measurement of contact angle.

The achieved contact angles $\left(138^{\circ}\right.$ for acidic and $143^{\circ}$ for basic) in case the coatings treated in acidic and basic medium reveal that the developed coating is not recommended operate in high acidic and alkaline mediums. It can be observed from the Fig. 9 that though the coating survives in the high $\mathrm{pH}$ environment, but still significant amount of damage has been occurred on the coating. It is expected that due to the reaction between $\mathrm{H}^{+}$or $\mathrm{OH}^{-}$ion with the elemental form of $\mathrm{Ni}$ and $\mathrm{Ti}$, the fine surface irregularities are expected to demolish. As a result, the roughness in micro-level converts to milli-level. The measurement of roughness on the chemical treated coating corroborates the statement given above (Fig. 10).

\section{Corrosion Analysis}

To measure the corrosion resistance of the developed coating, the coating was examined by electrochemical measurements. For this, $100 \mathrm{~mL}$ of aerated and unstirred $(3.5 \% \mathrm{NaCl})$ solution was used. A conventional electrochemical workstation (VERSASTAT3-400, PAR) having three electrode cells such as $\mathrm{Ag} / \mathrm{AgCl} / \mathrm{KCl}_{\text {saturated }}$ (reference electrode), a Pt wire (counter electrode) and the assprayed sample of $300 \mu \mathrm{m}$ thick (working electrode) has been used for the polarization test. The working electrode

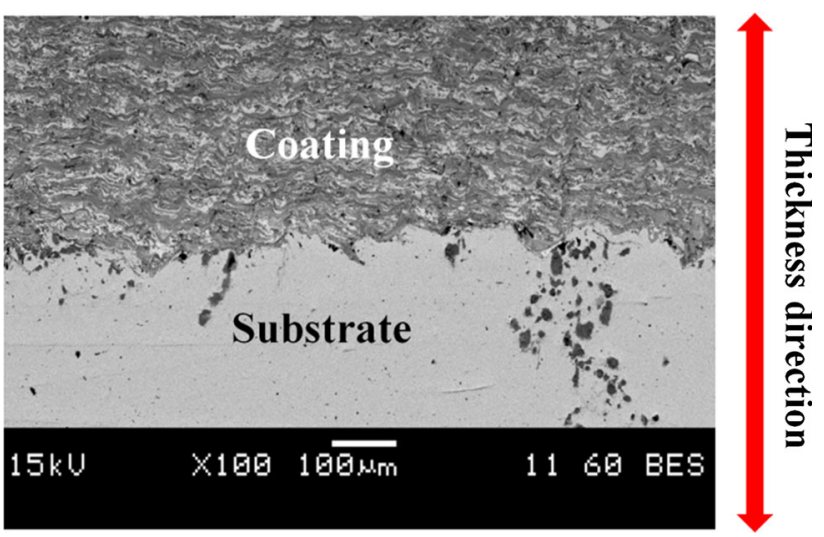

Fig. 16 SEM morphology at coating-substrate interface of NiTi plasma sprayed coating

was exposed to an area of $1 \mathrm{~cm}^{2}$ against the solution. The potentiodynamic curves were obtained from $-150 \mathrm{mV} /$ $E_{\mathrm{oc}}$ to $+1000 \mathrm{mV} / E_{\mathrm{oc}}$ at a scan rate of $0.166 \mathrm{mV} / \mathrm{s}$.

For the comparision of corrosion performance of NiTi plasma sprayed coating, a superhydrophobic coating by one-step immersion process has been prepared. This coating was synthesized on a brass substrate by simply immersing the substrate into $20 \mathrm{~g} / \mathrm{L}$ ethanoic solution lauric acid for $24 \mathrm{~h}$. After immersion, the samples were rinsed with distilled water to remove excess lauric acid solution followed by air dried for $24 \mathrm{~h}$ (Ref 66).

The polarization curve (Fig. 11) clearly indicates that the substrate corrodes very easily as compared to APS NiTi coating and antiwetting surface fabricated (by one-step) on brass substrate by simply immersion method. The abovestated statement is confirmed by analyzing the current density in the polarization curve. The current density of APS NiTi coating is least among the three samples.

As the current density decreases, a less number of ions are exposed to the surface. As a result, the probability of the interaction of the ion with the surface decline. In addition to the above, the potential value of the APS NiTi coating is more toward the positive side. Therefore, the APS NiTi coating is having more corrosion resistance than the uncoated surface and antiwetting surface.

\section{Stability of Superhydrophobicity in Open Atmosphere}

To check the stability of the superhydrophobicity of the coating in open atmosphere, the coating was exposed to the following atmospheric conditions (Table 4).

To check the stability of the superhydrophobicity of the coating in open air, the sample was exposed to open atmosphere over a period of 90 days, and periodically contact angles were measured (Table 5). It is observed that in open air, the coating retains its property up to 80 days 

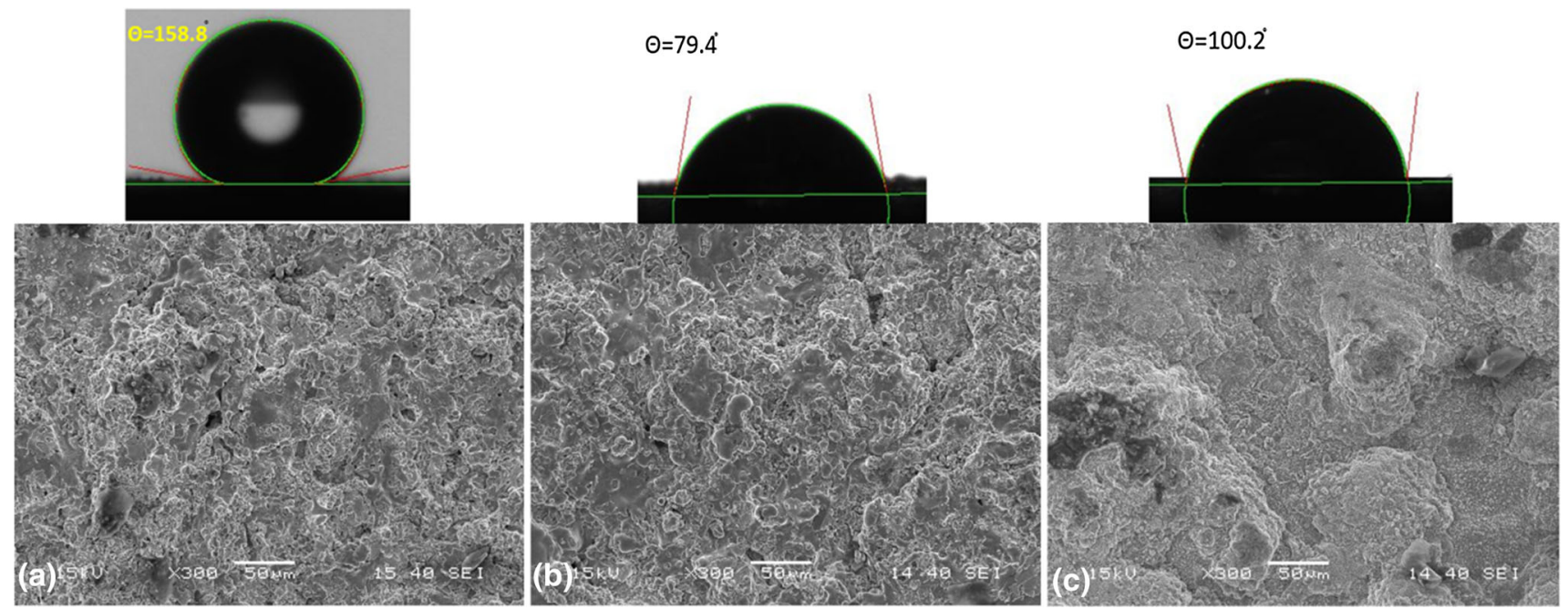

Fig. 17 SEM morphology $(\times 300)$ and contact angles of NiTi coating heated at temperatures of (a) $400{ }^{\circ} \mathrm{C}$, (b) $600{ }^{\circ} \mathrm{C}$ and (c) $900{ }^{\circ} \mathrm{C}$

Fig. 18 X-ray diffraction analysis of as-sprayed and heattreated samples (experimental condition: $2 \theta$ range $\left(20-110^{\circ}\right)$, scan rate $\left.\left(10^{\circ}\right) / \mathrm{min}\right)$ and step size $(0.02))$

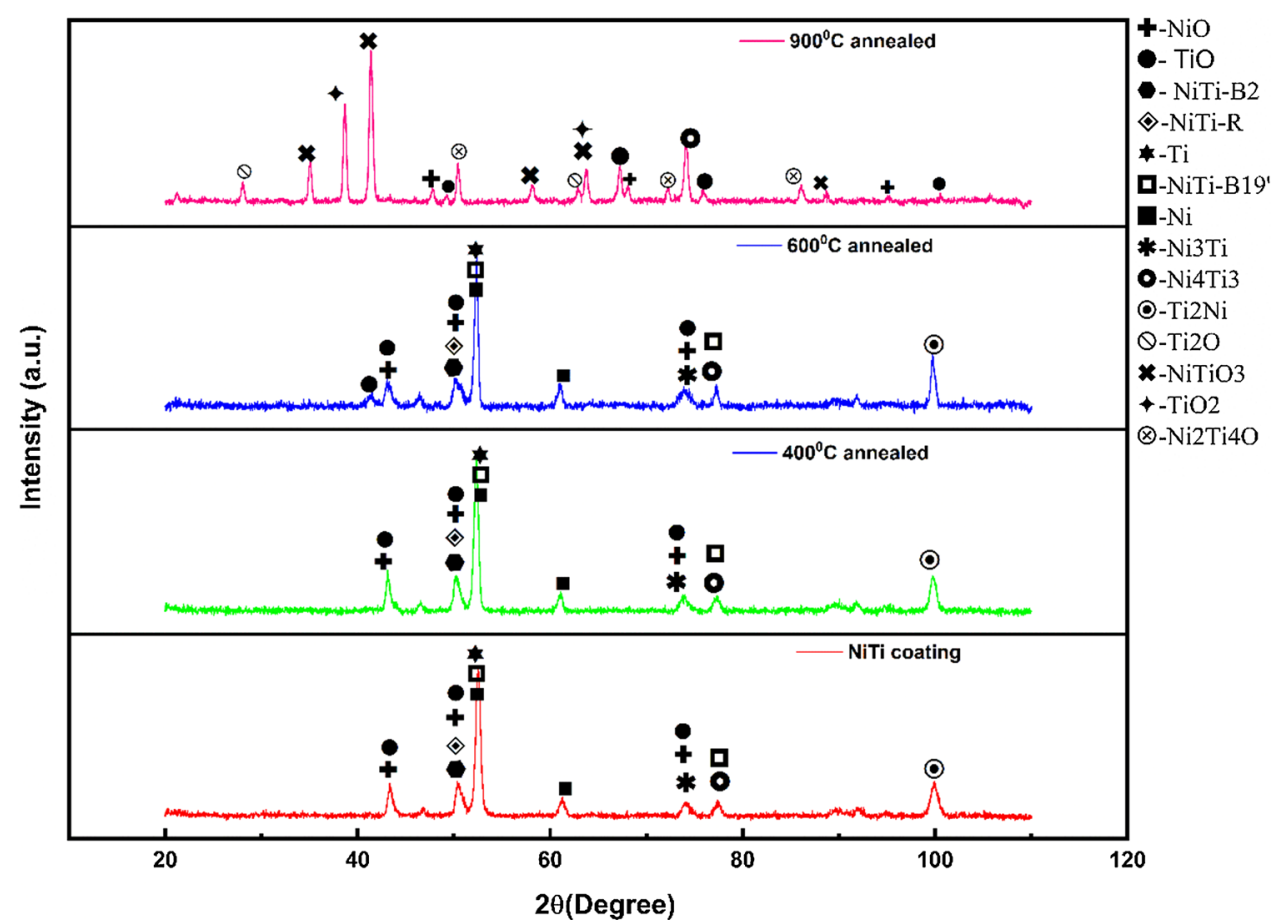

\section{Mechanical Stability Test}

and thereafter, coating starts losing its superhydrophobic characteristic. The possible reason behind the above-stated is the change in surface roughness of the coating by the deposition of suspended solids (Fig. 12). Furtehrmore, the coated surface is expected to oxidize due to the contact with the moisture present in air. The probability of loss of organic layer from the coating surface [which can be deposited by adsorption from air (Ref 43)] may also be considered another reason.

\section{Abrasion Test}

The abrasion resistance defining the operating condition of the plasma coating was determined by using a sand paper (Ref 67). Before investigation, the superhydrophobicity of the coating was ensured by measuring the contact angle, and then, with the help of sand paper the surface of the coating was tried to modify. The modification process includes the to-and-fro motion of the sand paper on the surface of the coating under a certain pressure of 
$346.5 \mathrm{kPa}$. After each cycle, which constitutes the movement of sand paper on the coating for a distance of $2 \times L$ ( $L$ is the length of the coating), the contact angle was measured. The variation of contact angle with the number of cycles used to modify the coated surface is presented in Fig. 13. Up to 90 cycles, the coating retains its superhydrophobicity and further increment demolishes the pillar and this is detrimental for superhydrophobic characteristic.

\section{Interfacial Bond Strength}

The evaluation of adhesive property of coating was performed as per ASTM C-633 (Ref 68). In the current testing, an indigenously designed and fabricated jig made up of mild steel was used (Fig. 14). The two dummies of the set up grip the coated sample and these were fixed by polymeric adhesive (epoxy 900-C). Then, the continuous tension was applied in the opposite direction until the plasma spray coating (as-sprayed) was detached from the substrate. To hold the coating properly, the dummies were roughened before applying the epoxy. In addition to the above, the coating pullout test was carried out by a universal tensile machine (UTM) with a crosshead speed of $10 \mathrm{~m} / \mathrm{min}$. The result reveals that at $40.85 \mathrm{MPa}$ tensile load (Fig. 15), the dummy detaches from the substrate.

The schematic depicting surface of the coated sample and the dummy is given in Fig. 14. It is observed that coating does not lose its adhesive property at the aforementioned conditions (confirmed by contact angle image Fig. 14). It can be observed from the cross sectional image (Fig. 16) that the absence of interfacial cracks and porosity in the coating leads to the strong adhesion between the substrate and coating. This could be due to the high molecular interaction at the coating and substrate interface.
Fig. 19 Visual observation of dropwise evaporation on coated and uncoated surface at $200{ }^{\circ} \mathrm{C}$

The interaction strength at the interface depends on the physiochemical surface forces such as Vander walls, covalent and ionic as well as the better interlocking of NiTi plasma deposition with the micron rough substrate surface. In the case of plasma coating, the bonding develops due to intermolecular solid diffusion and substrate coating interlocking. The elevated temperature of the plasma and the high pressure of plasma torch force the atoms of $\mathrm{Ni}$ and $\mathrm{Ti}$ to intersperse with the surface atoms of mild steel and to form a new grain boundary under the impact of creep.

\section{Thermal Stability Test}

Thermal stability test of the coating reveals the temperature range in which the coating remains unaffected. For the abovementioned investigation, the coating was heated to a predefined temperature (for $1 \mathrm{~h}$ ) and then after properly thermal soaked, it is kept in the furnace for cooling. After this, the contact angle on the coating was measured. In the current work, the considered temperature range is $100-900{ }^{\circ} \mathrm{C}$, and the step height of the temperature is $100{ }^{\circ} \mathrm{C}$. The analysis on the contact angle variation (Fig. 17) clearly ascertains that up to $400{ }^{\circ} \mathrm{C}$ the coating exhibits superhydrophobicity. Beyond the above-stated temperature, the superhydrophobic character is not found due to the extreme molecular vibration and organic migration on the surface. At very high temperature, molecular vibration occurs in the material for the transportation of heat. Due to this vibration, the deposited organic particles mentioned by $\mathrm{Li}$ et al. (Ref 43) are
Table 6 Types of phase formation and reference code of the phases formed in XRD of as-sprayed coating and annealed samples

\begin{tabular}{lll}
\hline \multicolumn{1}{c}{ Phases } & Reference code & \multicolumn{1}{c}{2 theta angle } \\
\hline $\mathrm{TiO}$ & $98-006-0480$ & $43.27^{\circ}, 50.40^{\circ}, 74.04^{\circ}$ \\
$\mathrm{NiO}$ & $98-005-9068$ & $43.55^{\circ}, 50.73^{\circ}, 74.56^{\circ}$ \\
$\mathrm{NiTi}(\mathrm{B} 2-$ phase) & $98-010-2932$ & $50.05^{\circ}$ \\
$\mathrm{Ni}$ & $98-009-0603$ & $52.32^{\circ}, 61.20^{\circ}$ \\
$\mathrm{Ti}$ & $98-002-3322$ & $52.32^{\circ}$ \\
$\mathrm{Ni}_{3} \mathrm{Ti}$ & $98-009-0780$ & $74.13^{\circ}$ \\
$\mathrm{Ni}_{4} \mathrm{Ti}_{3}$ & $98-012-2611$ & $77.31^{\circ}$ \\
$\mathrm{NiTi}(\mathrm{R}-\mathrm{phase})$ & $98-011-0091$ & $45.98^{\circ}, 50.13^{\circ}$ \\
$\mathrm{NiTi}^{\circ}\left(\mathrm{B} 19^{\prime}\right)$ & $98-011-0093$ & $52.6^{\circ}, 77.78^{\circ}$ \\
$\mathrm{Ti}_{2} \mathrm{Ni}$ & $98-007-5004$ & $100.08^{\circ}$ \\
$\mathrm{NiTiO}_{3}$ & $98-001-5438$ & $35.17^{\circ}, 41.45^{\circ}, 58.19^{\circ}, 63.72^{\circ}, 88.58^{\circ}$ \\
$\mathrm{Ti}_{2} \mathrm{O}$ & $98-000-7882$ & $28.12^{\circ}, 62.96^{\circ}$ \\
$\mathrm{TiO}_{2}$ & $98-001-7738$ & $38.73^{\circ}, 62.87^{\circ}$ \\
$\mathrm{Ni}_{2} \mathrm{Ti}_{4} \mathrm{O}$ & $98-001-1166$ & $50.39^{\circ}, 72.21^{\circ}, 86.06^{\circ}$ \\
\hline
\end{tabular}




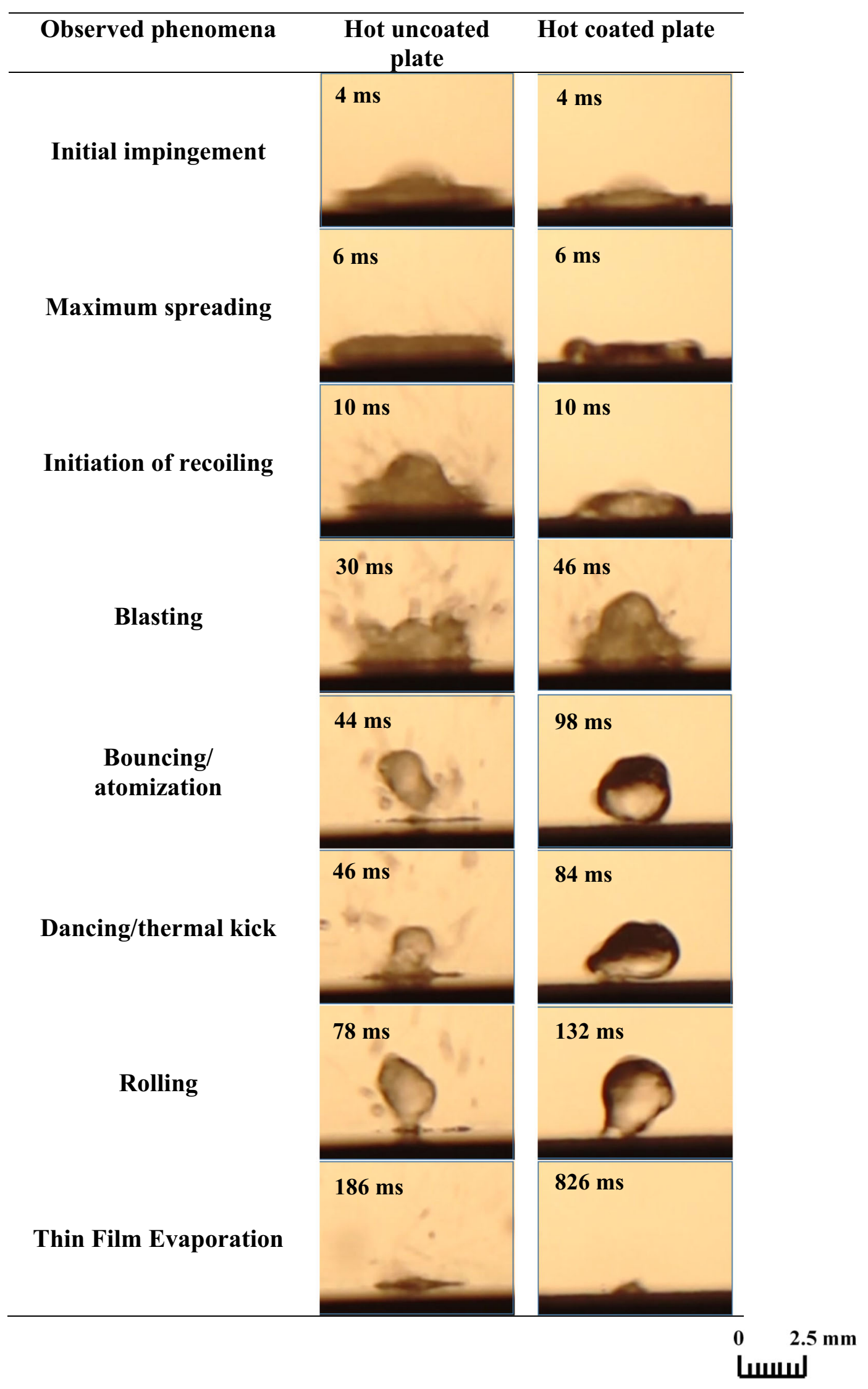


expected to remove. Further verification is performed by analyzing SEM images of coatings annealed at different temperatures (Fig. 17). These demonstrate that the demolished fine surface irregularities agglomerate which significantly reduces the surface roughness. Furthermore, the XRD results (Fig. 18) clearly corroborate the abovestated argument.

Above $600{ }^{\circ} \mathrm{C}$, the phase transformation of steel might enhance the molecular diffusion from the surface to the interior of the substrate and this can be considered another reason for the aforesaid variation. From XRD results (Table 6), it is noticed that mostly oxide phases are present in the material at $900{ }^{\circ} \mathrm{C}$. Among all the metal elements considered for the coating, titanium has a high affinity for the formation of oxides. Therefore, most of the oxides are $\mathrm{Ti}$ based. With the above oxide phases, $\mathrm{Ni}_{4} \mathrm{Ti}_{3}$ metastable phase is also identified at $900{ }^{\circ} \mathrm{C}$. In addition to the above, coatings annealed at or below $600{ }^{\circ} \mathrm{C}$ depict the similar type of trend and phases.

\section{Thermal Performance Evaluation}

To identify the thermal performance of the compressor blade, dropwise evaporative cooling experiments were conducted at transition and nucleate boiling regimes temperature. For the performances evaluation, the droplet impact mapping has been analyzed (Fig. 19). The investigation identifies various phenomena such as spreading, recoiling, bouncing, blasting, sliding and atomization which define qualitatively the heat removal process from the droplet to the hot plate.

From the droplet impact mapping, maximum favorable condition for heat transfer is observed in case of impingement of droplet on a coated plate. Furthermore, in this case, the minimum evaporation and the maximum recoiling are observed. To verify further, the droplet residence time and the cooling rate are also calculated, and these are presented in Table 7 . It clearly corroborates the discussion of droplet impact mapping. The evaporation of significant portion of droplet generates huge thermal stress in the plate, and as a consequence, the mechanical durability of the plate reduces. The thermal stresses are also calculated (using Eq 12) for the plate with and without coating (Table 8 ). It clearly reveals that due to the presence of coating the thermal stress is reduced up to 9.5 times than substrate $(\mathrm{Eq} 13)$.

The data of Table 8 were obtained by following the equation,

$\sigma=E \alpha \Delta T$

where $\sigma$ is the thermal stress, $E$ is Young's modulus, $\alpha$ is the coefficient of thermal expansion, $\Delta T$ is the temperature difference.
Table 7 Residence time and temperature drop of plate with and without coating

\begin{tabular}{lcc}
\hline \multicolumn{1}{c}{ Type of plates } & Residence time, ms & Cooling rate, ${ }^{\circ} \mathrm{C} / \mathrm{s}$ \\
\hline Plate without coating & 186 & 22 \\
Plate with coating & 132 & 5 \\
\hline
\end{tabular}

Table 8 Calculated thermal stress in plate with and without coating

\begin{tabular}{lcc}
\hline $\begin{array}{c}\text { Thermal stress developed } \\
\text { in steel plate }\end{array}$ & $\begin{array}{c}\text { Thermal stress } \\
\text { developed in coating }\end{array}$ & $\begin{array}{c}\text { Percentage } \\
\text { reduction }\end{array}$ \\
\hline $0.074 \mathrm{~N} / \mathrm{m}^{2}$ & $0.0078 \mathrm{~N} / \mathrm{m}^{2}$ & $98.94 \%$ \\
\hline
\end{tabular}

$\frac{\text { Themal stress developed in steel plate }}{\text { Thermal stress developed in coating }}=\frac{0.074}{0.0078}=9.5$

The temperature in the initial stage compressors of gas turbine engine maintains around $400{ }^{\circ} \mathrm{C}$ (Ref 69). As per the results in the current work, the coating retained its superhydrophobicity up to $400{ }^{\circ} \mathrm{C}$. In addition to the above, according to the literature, the average $\mathrm{pH}$ value of the acid rain is 4 ( $\operatorname{Ref} 70$ ); therefore, the initial stages of compressor blades of gas turbine should have the capability to withstand a $\mathrm{pH}$ of 4 . However, the current coating has been tested at $\mathrm{pH} 2$, which is in the strong acidic region. Furthermore, it is reported in the literature (Ref 71) that the erosion-corrosion phenomena on the compressor blades are due to the combined effect of impact of solid particles and electrochemical corrosion. In (Ref 31), we have concluded that the developed coating has excellent solid particle erosion resistance. So, the chances of penetration of the solid particles are very less. Therefore, it is expected that the current coating can be applied in the compressor blade of gas turbine engine and can sustain the effect of harsh environment.

\section{Conclusions}

In the current work, by using APS method and $\mathrm{Ni}$ and $\mathrm{Ti}$ powder, a superhydrophobic coating on mild steel substrate has been developed. Based on the characterization of the coated sample, the followings are the conclusion:

1. The developed coating ensures superhydrophobicity by depicting contact angle and sliding angle of $165^{\circ}$ and $8 \pm 1^{\circ}$, respectively. In addition to the above, the characterization performed on the coated sample corroborates the theory proposed in the literature for the attainment of superhydrophobicity. 
2. The adhesion test clearly ensures the failure of the coating under very high load (40.85 MPa). Although the coating can sustain an abrasion at a pressure of $346.5 \mathrm{kPa}$ for several passes, but it loses its superhydrophobic characteristic after 90 passes of abrasion on the sand paper.

3. The annealing test of the coating demonstrates that the superhydrophobic property of the coating retains up to $400{ }^{\circ} \mathrm{C}$ and beyond that, the coating converts to hydrophilic due to the formation of new compound and destruction of the pillar responsible for the surface irregularities defining surface roughness.

4. The coating is very much sensitive in alkaline $(\mathrm{pH}=$ $10)$ and acidic $(\mathrm{pH}=2)$ medium. The reductions in contact angle up to $138^{\circ}$ and $143^{\circ}$ are observed for abovementioned strong $\mathrm{pH}$ of acidic and basic mediums, respectively. This could be due to the dissolution of the roughness and also the conversion of the roughness from micro- to mili-range.

5. NiTi plasma coating depicts better corrosion resistance than substrate and superhydrophobic coating prepared by one-step immersion method.

6. The dropwise evaporation experiments on both coating and substrate ensure that coating allows lower heat absorption and this indirectly indicates better handling capacity of thermal shock.

7. The thermal stress developed in the substrate $(0.074 \mathrm{~N} /$ $\mathrm{m}^{2}$ ) is 9.5 times more than the thermal stress developed in the coating $\left(0.0078 \mathrm{~N} / \mathrm{m}^{2}\right)$ and this is desirable.

Acknowledgments All the spray coatings were prepared at thermal spray division of Hindustan Aeronautics Limited (HAL), Koraput, Odisha, India.

\section{References}

1. B.B. Michael Nosonovsky and Y.C. Jung, Lotus Effect: Roughness-Induced Superhydrophobicity. Nanotribol. Nanomech., 2008, p 995-1072. https://doi.org/10.1007/978-3-540-77608-6_19

2. L. Cao, A.K. Jones, V.K. Sikka, J. Wu, and D. Gao, Anti-icing Superhydrophobic Coatings, Langmuir, 2009, 25(21), p 1244412448

3. L. Zhai, F.C. Cebeci, R.E. Cohen, and M.F. Rubner, Stable Superhydrophobic Coatings from Polyelectrolyte Multilayers, Nano Lett., 2004, 4(7), p 1349-1353

4. A. Panda, A.R. Pati, B. Saha, A. Kumar, and S.S. Mohapatra, The Role of Viscous and Capillary Forces in the Prediction of Critical Conditions Defining Super-Hydrophobic and Hydrophilic Characteristics, Chem. Eng. Sci., 2019, 207, p 527-541. https://doi.org/ 10.1016/j.ces.2019.06.013

5. H. Wang, G. He, and Q. Tian, Effects of Nano-Fluorocarbon Coating on Icing, Appl. Surf. Sci., 2012, 258(18), p 7219-7224. https://doi.org/10.1016/j.apsusc.2012.04.043

6. L. Pan, S. Chen, T. Wang, J. Tao, H. Tao, and Y. Shen, Anti-icing Potential of Superhydrophobic Ti6Al4V Surfaces: Ice Nucleation and Growth, Langmuir, 2015, 31(39), p 10799-10806
7. J. Liu, Z. Janjua, F. Xu, K.-S. Choi, B. Turnbull, J. Liu, X. Hou, and M. Roe, Super-Hydrophobic/Icephobic Coatings Based on Silica Nanoparticles Modified by Self-assembled Monolayers, Nanomaterials, 2016, 6(12), p 232

8. S. Accretion, Aircraft Icing, Philos. Trans. R. Soc. A, 2017, 358(1776), p 2873-2911

9. J. Liu, J. Wang, H. Memon, Y. Fu, T. Barman, K.S. Choi, and X. Hou, Hydrophobic/Icephobic Coatings Based on Thermal Sprayed Metallic Layers with Subsequent Surface Functionalization, Surf. Coat. Technol., 2019, 357(October 2018), p 267272. https://doi.org/10.1016/j.surfcoat.2018.10.002

10. E. White, J. Gao, A. Martin, J. Locklin, and J. Yatvin, Permanently Grafted Icephobic Nanocomposites with High Abrasion Resistance, J. Mater. Chem. A, 2016, 4(30), p 11719-11728

11. V.S. Smitha, K.B. Jaimy, P. Shajesh, J.K. Jeena, and K.G. Warrier, UV Curable Hydrophobic Inorganic-Organic Hybrid Coating on Solar Cell Covers for Photocatalytic Self Cleaning Application, J. Mater. Chem. A, 2013, 1(40), p 12641-12649

12. R. Vaidhyanathan, B. Choksi, S. Shalini, S. Nandi, and D. Mullangi, Super-Hydrophobic Covalent Organic Frameworks for Chemical Resistant Coatings and Hydrophobic Paper and Textile Composites, J. Mater. Chem. A, 2017, 5(18), p 8376-8384

13. T. Cheng, R. He, Q. Zhang, X. Zhan, and F. Chen, Magnetic Particle-Based Super-Hydrophobic Coatings with Excellent Antiicing and Thermoresponsive Deicing Performance, J. Mater. Chem. A, 2015, 3(43), p 21637-21646

14. H. Zhou, H. Wang, H. Niu, A. Gestos, X. Wang, and T. Lin, Fluoroalkyl Silane Modified Silicone Rubber/Nanoparticle Composite: A Super Durable, Robust Superhydrophobic Fabric Coating, Adv. Mater., 2012, 24(18), p 2409-2412

15. X. Li and J. Shen, A Facile Two-Step Dipping Process Based on Two Silica Systems for a Superhydrophobic Surface, Chem. Commun., 2011, 47(38), p 10761-10763

16. J. Feng, M.T. Tuominen, and J.P. Rothstein, Hierarchical Superhydrophobic Surfaces Fabricated by Dual-Scale ElectronBeam-Lithography with Well-Ordered Secondary Nanostructures, Adv. Funct. Mater., 2011, 21(19), p 3715-3722

17. Y. Zhao, Z. Xu, X. Wang, and T. Lin, Superhydrophobic and UVBlocking Cotton Fabrics Prepared by Layer-by-Layer Assembly of Organic UV Absorber Intercalated Layered Double Hydroxides, Appl. Surf. Sci., 2013, 286, p 364-370. https://doi.org/10. 1016/j.apsusc.2013.09.092

18. M. Ma, Y. Mao, M. Gupta, K.K. Gleason, and G.C. Rutledge, Superhydrophobic Fabrics Produced by Electrospinning and Chemical Vapor Deposition, Macromolecules, 2005, 38(23), p 9742-9748. https://doi.org/10.1021/ma0511189

19. S.A. Mahadik, M.S. Kavale, S.K. Mukherjee, and A.V. Rao, Transparent Superhydrophobic Silica Coatings on Glass by SolGel Method, Appl. Surf. Sci., 2010, 257(2), p 333-339. https://doi. org/10.1016/j.apsusc.2010.06.062

20. C. Jeong and C.H. Choi, Single-Step Direct Fabrication of Pillaron-Pore Hybrid Nanostructures in Anodizing Aluminum for Superior Superhydrophobic Efficiency, ACS Appl. Mater. Interfaces., 2012, 4(2), p 842-848

21. S.E. Lee, K.W. Lee, J.H. Kim, K.C. Lee, S.S. Lee, and S.U. Hong, Mass-Producible Superhydrophobic Surfaces, Chem. Commun., 2011, 47(43), p 12005-12007

22. C.H. Xue, X.J. Guo, J.Z. Ma, and S.T. Jia, Fabrication of Robust and Antifouling Superhydrophobic Surfaces via Surface-Initiated Atom Transfer Radical Polymerization, ACS Appl. Mater. Interfaces., 2015, 7(15), p 8251-8259

23. X. Zhang, Z. Li, K. Liu, and L. Jiang, Bioinspired Multifunctional Foam with Self-cleaning and Oil/Water Separation, $A d v$. Funct. Mater., 2013, 23(22), p 2881-2886 
24. Y. Li, S. Chen, M. Wu, and J. Sun, All Spraying Processes for the Fabrication of Robust, Self-healing, Superhydrophobic Coatings, Adv. Mater., 2014, 26(20), p 3344-3348

25. D. Framil Carpeño, M. Dickinson, C. Seal, and M. Hyland, Induced Hydrophobicity in Micro- and Nanostructured Nickel Thin Films Obtained by Ultraviolet Pulsed Laser Treatment, Phys. Status Solidi Appl. Mater. Sci., 2016, 213(10), p 2709-2713

26. G. Azimi, R. Dhiman, H.M. Kwon, A.T. Paxson, and K.K. Varanasi, Hydrophobicity of Rare-Earth Oxide Ceramics, Nat. Mater., 2013, 12(4), p 315-320. https://doi.org/10.1038/nmat3545

27. P. Mallick, B. Behera, S.K. Patel, B. Swain, R. Roshan, and A. Behera, Plasma Spray Parameters to Optimize the Properties of Abrasion Coating Used in Axial Flow Compressors of AeroEngines to Maintain Blade Tip Clearance, Mater. Today Proc., 2020, https://doi.org/10.1016/j.matpr.2020.03.835

28. B. Behera, P. Mallick, B. Swain, S. Kumar Patel, R. Roshan, and A. Behera, Surface Modified Mild Steel and Copper Using Homogenized Fly-Ash + Quartz + Ilmenite by Plasma Technology, Mater. Today Proc., 2020, https://doi.org/10.1016/j. matpr.2020.04.526

29. S.K. Bhuyan, S. Samal, D. Pattnaik, A. Sahu, B. Swain, T.K. Thiyagarajan, and S.C. Mishra, Effect of Bauxite Addition on Adhesion Strength and Surface Roughness of Fly Ash Based Plasma Sprayed Coatings, in IOP Conference Series: Materials Science and Engineering, 2018

30. A.B. Biswajit Swain, S. Patel, P. Mallick, and S.S. Mohapatra, Solid Particle Erosion Wear of Plasma Sprayed NiTi Alloy Used for Aerospace Applications, ITSC 2019-Proceedings of the International Thermal Spray Conference, 2019, p 346-351

31. B. Swain, P. Mallick, S.K. Bhuyan, S.S. Mohapatra, S.C. Mishra, and A. Behera, Mechanical Properties of NiTi Plasma Spray Coating, J. Therm. Spray Technol., 2020, 29(4), p 741-755. https://doi.org/10.1007/s11666-020-01017-6

32. B. Kumar, S. Soumya, S. Mohapatra, and G. Power, Sensitivity of Process Parameters in Atmospheric Plasma Spray Coating, $J$. Therm. Spray Eng., 2018, 1(1), p 1-6

33. B. Swain, S. Bajpai, and A. Behera, Microstructural Evolution of NITINOL and Their Species Formed by Atmospheric Plasma Spraying, Surf. Topogr. Metrol. Prop., 2018, 7(1), p 015006. https://doi.org/10.1088/2051-672x/aaf30e

34. B. Swain, A. Patnaik, S.K. Bhuyan, K.N. Barik, S.K. Sethi, S. Samal, S.C. Mishra, and A. Behera, Solid Particle Erosion Wear on Plasma Sprayed Mild Steel and Copper Surface, Mater. Today Proc., 2018, 5(9), p 20403-20412

35. B. Swain, P. Mallick, S. Patel, R. Roshan, S.S. Mohapatra, S. Bhuyan, M. Priyadarshini, B. Behera, S. Samal, and A. Behera, Failure Analysis and Materials Development of Gas Turbine Blades, Mater. Today Proc., 2020, https://doi.org/10.1016/j. matpr.2020.02.859

36. A. Koutsomichalis, N. Vaxevanidis, G. Petropoulos, E. Xatzaki, A. Mourlas, and S. Antoniou, Tribological Coatings for Aerospace Applications and the Case of WC-Co Plasma Spray Coatings, Tribol. Ind., 2009, 31(1-2), p 37-42

37. K. Jafarzadeh, Z. Valefi, and B. Ghavidel, The Effect of Plasma Spray Parameters on the Cavitation Erosion of $\mathrm{Al}_{2} \mathrm{O}_{3}-\mathrm{TiO}_{2}$ Coatings, Surf. Coat. Technol., 2010, 205(7), p 1850-1855. https://doi.org/10.1016/j.surfcoat.2010.08.044

38. W. Xue, X. Liu, X. Zheng, and C. Ding, Plasma-Sprayed Diopside Coatings for Biomedical Applications, Surf. Coat. Technol., 2004, 185(2-3), p 340-345. https://doi.org/10.1016/j.surfcoat. 2003.12.018

39. G. Barbezat and G. Wuest, Advantages for Automotive Industry of Plasma Spray Coating of Ai-Si Cast Alloy Cylinder Bores, Surf. Eng., 1998, 14(2), p 113-116. https://doi.org/10.1179/sur. 1998.14.2.113
40. N. Sharifi, M. Pugh, C. Moreau, and A. Dolatabadi, Developing Hydrophobic and Superhydrophobic $\mathrm{TiO}_{2}$ Coatings by Plasma Spraying, Surf. Coat. Technol., 2016, 289, p 29-36. https://doi. org/10.1016/j.surfcoat.2016.01.029

41. H. Huang, Y. An, X. Hu, D. Wu, H. Cao, X. Zhang, J. Qiao, and H. Liu, A Plasma Sprayed Superhydrophobic Coating Prepared with $\mathrm{Al} @ \mathrm{WO}_{3}$ Core-Shell Powder and Photocatalytic Degradation Performance, Surf. Coat. Technol., 2019, 369, p 105-115. https://doi.org/10.1016/j.surfcoat.2019.04.055

42. S. Li, P. Li, Y. Tian, and Y. Zheng, Fluffy Polyfluoroalkoxy Layer Produced by Air Plasma Spraying Based on "Grapeshot" Effect, J. Therm. Spray Technol., 2020, 29(3), p 462-470. https:// doi.org/10.1007/s11666-019-00965-y

43. Z. Li, Y. Zheng, J. Zhao, and L. Cui, Wettability of Atmospheric Plasma Sprayed Fe, Ni, Cr and Their Mixture Coatings, J. Therm. Spray Technol., 2012, 21(2), p 255-262

44. A. Ölander, An Electrochemical Investigation of Solid Cadmium-Gold Alloys, J. Am. Chem. Soc., 1932, 54(10), p 38193833

45. S. Kumar Patel, B. Swain, R. Roshan, N.K. Sahu, and A. Behera, A Brief Review of Shape Memory Effects and Fabrication Processes of NiTi Shape Memory Alloys, Mater. Today Proc., 2020, https://doi.org/10.1016/j.matpr.2020.03.539

46. S.K. Patel, B. Behera, B. Swain, R. Roshan, D. Sahoo, and A. Behera, A Review on NiTi Alloys for Biomedical Applications and Their Biocompatibility, Mater. Today Proc., 2020, https:// doi.org/10.1016/j.matpr.2020.03.538

47. Z. Li, Y. Zheng, and L. Cui, Preparation of Metallic Coatings with Reversibly Switchable Wettability Based on Plasma Spraying Technology, J. Coat. Technol. Res., 2012, 9(5), p 579587

48. P. Xu, L. Pershin, J. Mostaghimi, and T.W. Coyle, Efficient OneStep Fabrication of Ceramic Superhydrophobic Coatings by Solution Precursor Plasma Spray, Mater. Lett., 2018, 211, p 2427. https://doi.org/10.1016/j.matlet.2017.09.077

49. M.K. Stanford, Hardness and Microstructure of Binary and Ternary Nitinol Compounds, Nasa/Tm-2016-218946, 2016, p 46. http://www.sti.nasa.gov

50. C.N. Saikrishna, K.V. Ramaiah, A.S. Prabhu, and S.K. Bhaumik, On Stability of NiTi Wire During Thermo-Mechanical Cycling, Bull. Mater. Sci., 2009, 32(3), p 343-352

51. K. Mehrabi, M. Bruncko, and A.C. Kneissl, Microstructure, Mechanical and Functional Properties of NiTi-Based Shape Memory Ribbons, J. Alloys Compd., 2012, 526, p 45-52. https:// doi.org/10.1016/j.jallcom.2012.02.097

52. J.M. Guilemany, N. Cinca, S. Dosta, and A.V. Benedetti, Corrosion Behaviour of Thermal Sprayed Nitinol Coatings, Corros. Sci., 2009, 51(1), p 171-180. https://doi.org/10.1016/j.corsci. 2008.10.022

53. M.M. Verdian, K. Raeissi, and M. Salehi, Corrosion Performance of HVOF and APS Thermally Sprayed NiTi Intermetallic Coatings in $3.5 \% \mathrm{NaCl}$ Solution, Corros. Sci., 2010, 52(3), p 10521059. https://doi.org/10.1016/j.corsci.2009.11.034

54. S. Sampath and H. Herman, Rapid Solidification and Microstructure Development During Plasma Spray Deposition, $J$. Therm. Spray Technol., 1996, 5(4), p 445-456

55. M.M. Verdian, K. Raeissi, and M. Salehi, Electrochemical Impedance Spectroscopy of HVOF-Sprayed NiTi Intermetallic Coatings Deposited on AISI, 1045 Steel, J. Alloys Compd., 2010, 507(1), p 42-46. https://doi.org/10.1016/j.jallcom.2010.07.132

56. C.W. Kang and H.W. Ng, Splat Morphology and Spreading Behavior Due to Oblique Impact of Droplets onto Substrates in Plasma Spray Coating Process, Surf. Coat. Technol., 2006, 200(18-19), p 5462-5477

57. H.R. Salimijazi, L. Pershin, T.W. Coyle, J. Mostaghimi, S. Chandra, Y.C. Lau, L. Rosenzweig, and E. Moran, Effect of 
Droplet Characteristics and Substrate Surface Topography on the Final Morphology of Plasma-Sprayed Zirconia Single Splats, $J$. Therm. Spray Technol., 2007, 16(2), p 291-299

58. C.C. Berndt and R. McPherson, Fracture Mechanics Approach to the Adhesion of Flame and Plasma Sprayed Coatings, Mech. Eng. Trans. Inst. Eng. Aust., 1981, ME6(1), p 53-58

59. F.N. Oktar, M. Yetmez, S. Agathopoulos, T.M.L. Goerne, G. Goller, I. Ipeker, and J.M.F. Ferreira, Bond-Coating in PlasmaSprayed Calcium-Phosphate Coatings, J. Mater. Sci. Mater. Med., 2006, 17(11), p 1161-1171

60. P. Taylor and L. Jack, Journal of Metals 1950-The Structure of Intermediate Phases in Alloys of Titanium with Iron, Cobalt Nickel, 1950, 188(October), p 1173-1176

61. Z. Zeng, S. Kuroda, and H. Era, Comparison of Oxidation Behavior of Ni-20Cr Alloy and Ni-Base Self-fluxing Alloy During Air Plasma Spraying, Surf. Coat. Technol., 2009, 204(12), p 69-77

62. A.T.T. Tran, M.M. Hyland, T. Qiu, B. Withy, and B.J. James, Effects of Surface Chemistry on Splat Formation During Plasma Spraying, J. Therm. Spray Technol., 2008, 17(5), p 637-645

63. M. Bram, A. Ahmad-Khanlou, H.P. Buchkremer, and D. Stöver, Vacuum Plasma Spraying of NiTi Protection Layers, Mater. Lett., 2002, 57(3), p 647-651

64. H.-B. Xiong, L.-L. Zheng, L. Li, and A. Vaidya, Melting and Oxidation Behavior of In-Flight Particles in Plasma Spray Process, Int. J. Heat Mass Transf., 2005, 48(25-26), p 5121-5133

65. P. Fauchais, Understanding Plasma Spraying, J. Phys. D Appl. Phys., 2004, 37(9), p R86-R108

66. P. Varshney and S.S. Mohapatra, Durable and Regenerable Superhydrophobic Coatings for Brass Surfaces with Excellent
Self-cleaning and Anti-fogging Properties Prepared by Immersion Technique, Tribol. Int., 2018, 123(February), $\mathrm{p}$ 17-25. https://doi.org/10.1016/j.triboint.2018.02.036

67. X. Chen, Y. Gong, X. Suo, J. Huang, Y. Liu, and H. Li, Construction of Mechanically Durable Superhydrophobic Surfaces by Thermal Spray Deposition and Further Surface Modification, Appl. Surf. Sci., 2015, 356, p 639-644. https://doi.org/10.1016/J. APSUSC.2015.08.156

68. X. Zheng, M. Huang, and C. Ding, Bond Strength of PlasmaSprayed Hydroxyapatite/Ti Composite Coatings, Biomaterials, 2000, 21(8), p 841-849

69. V. Bonu, M. Jeevitha, V. Praveen-Kumar, and H.C. Barshilia, Nanolayered Multilayer Ti/TiN Coatings: Role of Bi-Layer Thickness and Annealing on Solid Particle Erosion Behaviour at Elevated Temperature, Surf. Coat. Technol., 2019, 357, p 204211. https://doi.org/10.1016/j.surfcoat.2018.10.007

70. H. Terada, H. Ueda, and Z. Wang, Trend of Acid Rain and Neutralization by Yellow Sand in East Asia-A Numerical Study, Atmos. Environ., 2002, 36(3), p 503-509. https://doi.org/ 10.1016/S1352-2310(01)00509-X

71. Z.B. Zheng, Y.G. Zheng, X. Zhou, S.Y. He, W.H. Sun, and J.Q. Wang, Determination of the Critical Flow Velocities for ErosionCorrosion of Passive Materials under Impingement by $\mathrm{NaCl}$ Solution Containing Sand, Corros. Sci., 2014, 88, p 187-196. https://doi.org/10.1016/j.corsci.2014.07.043

Publisher's Note Springer Nature remains neutral with regard to jurisdictional claims in published maps and institutional affiliations. 